Karla Rodrigues Cavalcante

\title{
Avaliação do desempenho de idosos normais em um protocolo de produção e reconhecimento de gestos: influência do sexo, da idade e escolaridade no perfil de normalidade
}

Dissertação apresentada ao Departamento de Neurologia da Faculdade de Medicina da Universidade de São Paulo para obtenção do título de Mestre em Ciências

Área de concentração: Neurologia

Orientador: Dr. Paulo Caramelli 


\section{DEDICATÓRIA}

Aos meus pais por me ensinarem o verdadeiro valor do conhecimento e me incentivarem durante toda a minha formação. 


\section{AGRADECIMENTOS}

A Deus, pela vida e por tudo de melhor que nela se encerra. Por sua presença constante ao meu lado.

Ao meu orientador Dr Paulo Caramelli, pela paciência, dedicação, sabedoria e principalmente por saber tão bem dividir seu imenso conhecimento.

Aos idosos que participaram desse estudo pela paciência, carinho e pelas muitas lições de vida.

À minha mãe, por tudo mesmo. Pela valiosa ajuda na busca dos sujeitos, por estar ao meu lado sempre, por ser meu porto seguro.

Aos meus irmãos Katarina e Ricardo por acreditarem em mim, pela paciência e pelas inúmeras idas à biblioteca.

Aos meus avós Maria e Hélio pela simpatia e preocupação e também por me ajudarem muito na busca dos sujeitos.

Ao Marcelinho, pelo ser humano maravilhoso que é e por todo amor, carinho, compreensão, paciência e presença em todos os momentos desse trabalho.

À minha amiga/irmã Juliana Rodrigues Pegas por todo amor, incentivo, companheirismo, presença apoio e cobertura durante a realização do trabalho.

À minha super amiga Janaina Namba pela paciência, pela experiência e por saber sempre falar a coisa certa na hora certa.

Às queridas amigas do setor de neurologia da UNITAU Daniela Alves Soares e Karla Garcez Cusmanich por dividirem comigo no dia a dia todos os momentos, bons e ruins. Pela "cobertura" nas minhas ausências e por me ajudarem imensamente na localização dos sujeitos.

Às amigas e pós-graduandas Danielle Rüegg e Thaís Machado pelo carinho, apoio amizade e pela vivência conjunta de todas as etapas desse processo.

\section{A todos os que me ajudaram na localização dos sujeitos especialmente: Luciana Simone, Regina e Benedito Perotti, Prof. Dra. Letícia Mansur, Maria Paula do Amaral Zaitune e às alunas: Karina, Ana Paula e Gabriela.}

A banca da qualificação pelas valiosas sugestões. 
Ao grupo anos dourados e especialmente à assistente social Lúcia Zani pelo imenso carinho com que fui acolhida e pela preciosa contribuição dos idosos.

Ao Grupo Vida de Barueri pela ajuda na localização dos sujeitos e por me acolher com tanta disponibilidade e simpatia.

Ao secretario do departamento de Neurologia Erli Vieria Soares Junior pela atenção e simpatia de sempre.

A estatística Patrícia Ramos pela paciência e pelo auxílio incalculável.

As bibliotecárias Marinalva de Souza Aragão e Valéria Vilhena por toda a ajuda prestada durante todo o processo de revisão bibliográfica.

Ao Prof. Gerval de Almeida pelo apoio e incentivo.

A todas as pessoas que de alguma forma contribuíram para que esse trabalho se realizasse. 
Esta dissertação está de acordo com:

Referências: adaptado de International Committee of Medical Journals Editors (Vancouver)

Universidade de São Paulo. Faculdade de Medicina. Serviço de Biblioteca e Documentação. Guia de apresentação de dissertações, teses e monografias. Elaborado por Anneliese Carneiro da Cunha, Maria Júlia de A.L. Freddi, Maria F Crestana, Marinalva de Souza Aragão, Suely Campos Cardoso, Valéria Vilhena. São Paulo: Serviço de Biblioteca e Documentação; 2004.

Abreviaturas dos títuos dos periódicos de acordo com List of Journals Indexed in Index Medicus. 


\section{RESUMO}

Cavalcante KR. Avaliação do desempenho de idosos normais em um protocolo de produção e reconhecimento de gestos: influência do sexo, da idade e escolaridade no perfil de normalidade.

A apraxia é uma desordem dos movimentos aprendidos que não é resultado de fraqueza ou alteração sensitiva. Esta alteração pode ser devida a um prejuízo na execução têmporo-espacial ou na própria elaboração do gesto. Um protocolo de avaliação de praxias deve conter elementos que sejam capazes de avaliar o sistema executivo sem a interferência do sistema conceitual e vice-versa. Para isso o sujeito deve produzir gestos, bem como deve ser capaz de reconhecê-los. Contudo essa avaliação pode sofrer influência de variáveis como a idade, o sexo e a escolaridade. Esse trabalho tem como objetivo avaliar a influência das variáveis sexo, idade e escolaridade no desempenho de indivíduos idosos saudáveis em um protocolo de produção e reconhecimento de gestos, bem como a confiabilidade intra e interexaminador do protocolo de produção e a confiabilidade intra-examinador do protocolo de reconhecimento. Para isso foram avaliados 96 indivíduos divididos em dois grupos. Um grupo formado por indivíduos com idades de 60 a 74 anos e outro grupo formado por indivíduos com idades iguais ou superiores a 75 anos. Cada grupo era formado por um número igual de homens e mulheres e era subdivido em quatro grupos de acordo com a escolaridade: analfabetos, de 1 a 3 anos, de 4 a 7 anos e igual ou superior a 8 anos. No protocolo de produção de gestos solicitava-se aos indivíduos que realizassem gestos ao comando verbal e à imitação. No protocolo de reconhecimento, o indivíduo assistia a um vídeo no qual ele deveria ser capaz de discriminar gestos conhecidos de desconhecidos, gestos bem realizados de mal realizados, associar gestos a objetos, bem como nomear gestos. Os resultados revelaram que tanto a idade quanto a escolaridade influenciaram o desempenho no protocolo de produção de gestos. Os gestos ao comando verbal obtiveram menor porcentagem de acerto do que os gestos realizados à imitação. Já no protocolo de reconhecimento, as três variáveis influenciaram de forma significativa o desempenho. A análise final mostrou que, levando-se em conta a escolaridade, podemos observar três grandes grupos: os analfabetos, os indivíduos que estudaram de 1 a 7 anos e aqueles com oito ou mais anos de escolaridade. Também mostrou que 
os indivíduos mais velhos, a exemplo da produção, apresentam pior desempenho e que mulheres reconhecem mais gestos do que homens. Os achados estão de acordo com relatos de que o aumento da idade, a diminuição da escolaridade e mesmo o sexo são fatores capazes de influenciar o desempenho dos indivíduos em testes neuropsicológicos. O protocolo de produção apresentou elevada confiabilidade, tanto intra quanto inter-examinador, além de excelente consistência interna. O protocolo de reconhecimento também apresentou resultados satisfatórios tanto de confiabilidade inter-examinador quanto de consistência interna.

Descritores: Idoso, gestos, recursos audiovisuais/normas, desempenho psicomotor, estudos de avaliação, escolaridade, apraxias. 


\section{SUMMARY}

Cavalcante, KR. Evaluation of the performance of normal elderly in a protocol of gesture production and recognition: influence of age, gender and education.

Apraxia is a loss of the ability to perform learned skill movements when this loss cannot be accounted for by elemental motor deficits, such as weakness or sensory deficits. This disorder could result in damage of the spatiotemporal characteristics of the execution of the movement or in the proper elaboration of the gesture. A protocol of praxis evaluation must contain elements that are capable to evaluate the executive system without interference from the conceptual system and vice versa. For this purpose, subjects must produce gestures, and also recognize them. Nevertheless, this evaluation can suffer influence from variables such as age, gender and education. The goals of this work were to evaluate the influence of the variables gender, age and education in the performance of healthy elderly individuals in a protocol of gesture production and recognition, as well as the intra- and inter-examiner reliability of the production protocol and the intraexaminer reliability of the recognition protocol. For this 96 individuals divided in two groups were evaluated. A group (A) formed by subjects aged 60 to 74 years and another group formed by individuals aged 75 years or over. Each group was formed by an equal number of men and women and it was subdivides in four groups in accordance with the educational level of the subjects: illiterates, 1 to 3 years, 4 to 7 years and 8 or more years of schooling. In gesture production, individuals were requested to accomplish the tasks on verbal command and imitation. In the recognition protocol the individuals should watch a video in which they were asked to discriminate between known and unknown gestures, discriminate between correctly and incorrectly performed acts, to associate gestures to objects, as well as to perform gesture naming. The results revealed that age as well as educational level influence the performance in the protocol of gesture production. Gesture performance on verbal command was more difficult than on imitation. On the recognition protocol, the three variables significantly influence the performance. The final analysis showed that taking into account the educational level, three major groups emerged: the illiterates, the individuals with 1 to 7 years and those with eight or more years of schooling. The older individuals, similar to what was observed in the production protocol, presented worse performance than their younger counterparts, and women were able to recognize more gestures than men. These findings are in agreement with studies showing that with the increase of the age, the decrease of formal education and gender are factors that influence the performance of the individuals in neuropsychological tests. The production protocol presented both high intra- and inter-rater reliability and excellent internal consistency. The recognition protocol also showed adequate interexaminer reliability as well as good internal consistency. 
Key words: aged, gestures, audiovisual aids/standards, psychomotor performance, evaluation studies, educational status, apraxias. 


\section{Sumário}

1. INTRODUÇÃ

1.1 A ELABORAÇÃO E A EXECUÇÃO DOS GESTOS ……………………………........16

1.2 INSTRUMENTOS DE AVALIAÇÃO DE PRAXIAS DE MEMBROS. ...................................30

2. OBJETIVO ................................................................................................................................37

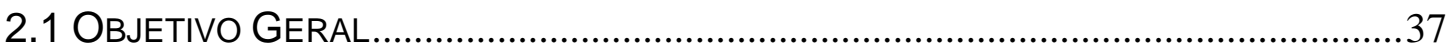

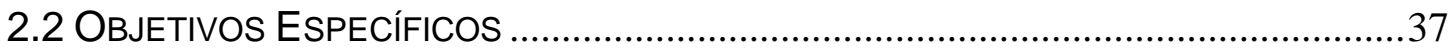

3. CASUÍSTICA E MÉTODOS .......................................................................38

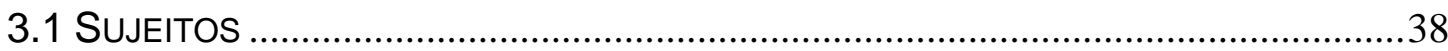

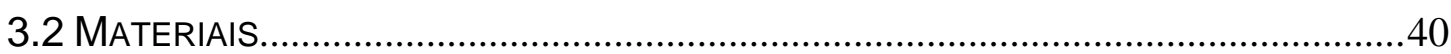

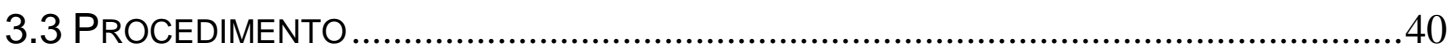

3.3.1 PROTOCOLO AVALIAÇÃO DE PRODUÇÃO DE GESTOS (SKA ET AL., 1997) .........40

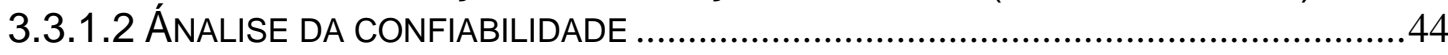

3.3.2 TESTE DE RECONHECIMENTO DOS GESTOS (ROCK E SKA, 1994)....44

3.3.2.1 PRIMEIRA PROVA: RECONHECIMENTO DE GESTOS ......................................45

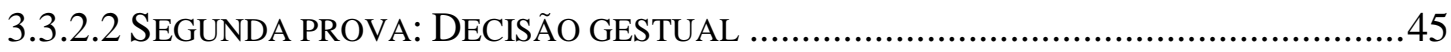

3.3.2.3 TERCEIRA PROVA: JULGAMENTO DE SIMILARIDADE ……………………….......46

3.3.2.4 QUARTA PROVA: SELEÇÃO DO GESTO CORRETO ………………………….........47

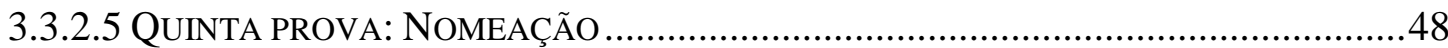

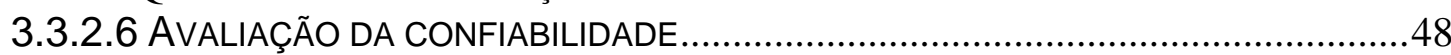

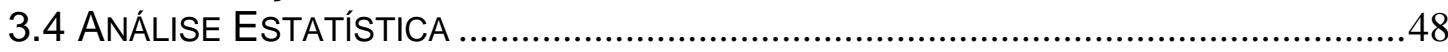

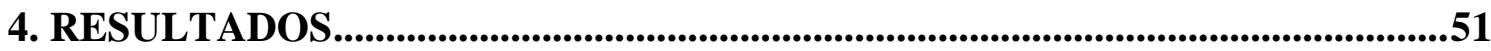

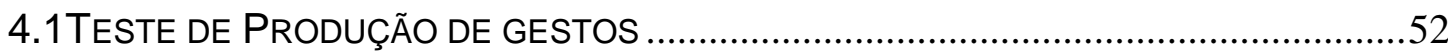

4.1.1 CORRELAÇÃO ENTRE OS TESTES DE RASTREIO E A PRODUÇÃO DE GESTOS..............56

4.1.2 CONFIABILIDADE INTER E INTRA-EXAMINADOR. ……………...........................57

4.2 TESTE DE RECONHECIMENTO DE GESTOS. ......................................................5

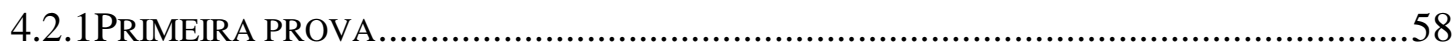

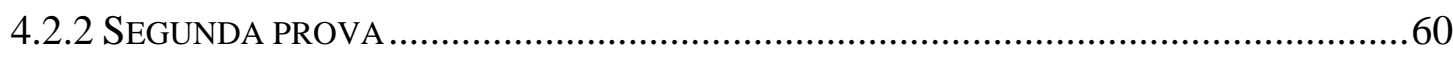

4.2.2.1 PRIMEIRA PARTE - GESTOS TRANSITIVOS .........................................................61

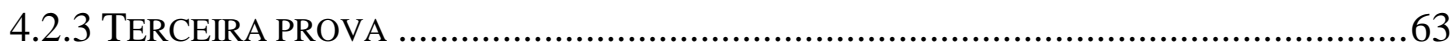

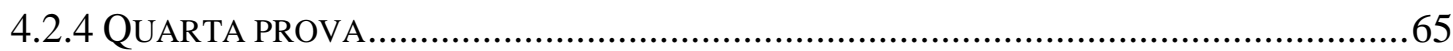

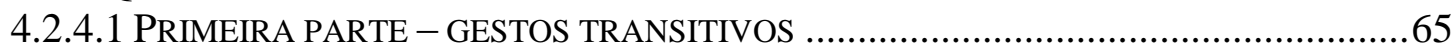

4.2.4.2 SEGUNDA PROVA - GESTOS CONVENCIONAIS...................................................66

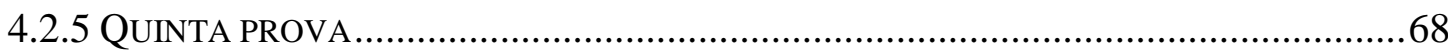

4.2.6 CORRELAÇÃO ENTRE TESTES DE RASTREIO E PRODUÇÃO DE GESTOS.......................70

4.2.7 CONFIABILIDADE INTRA-EXAMINADOR. ……………....................................

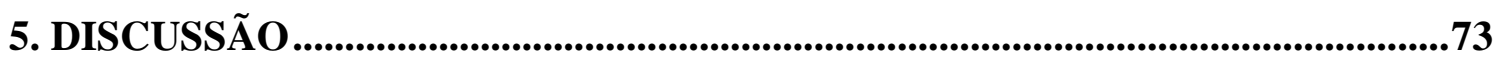

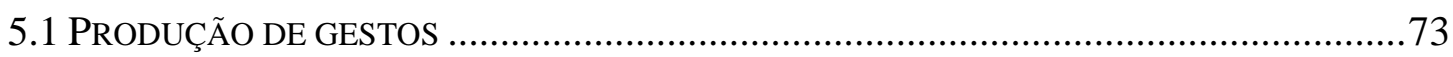

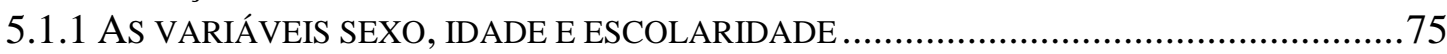

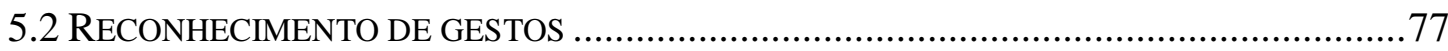

5.2.1 AS VARIÁVEIS SEXO, IDADE, E ESCOLARIDADE ………………………................. 
5.2.2 GESTOS TRANSITIVOS X GESTOS CONVENCIONAIS 85

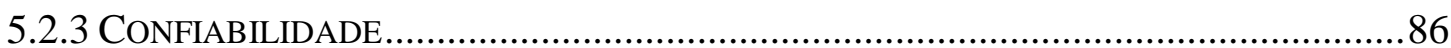

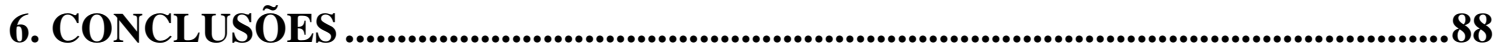

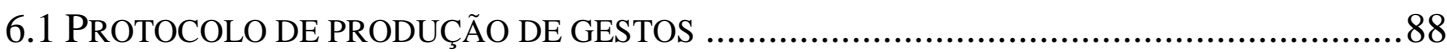

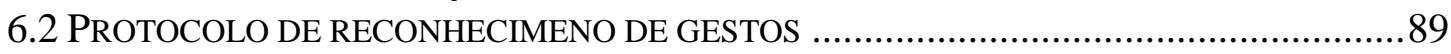

7. REFERÊNCIAS BIBLIOGRÁFICAS ........................................................................90 


\section{INTRODUÇÃO}

Para o ser humano o movimento é peça fundamental na interação com o meio ambiente e com outros indivíduos. Para que o movimento tome forma é necessário o envolvimento de várias estruturas anatômicas como o córtex cerebral, núcleos da base, cerebelo, tronco encefálico, medula espinhal, nervo periférico até que o músculo, órgão efetor final, seja alcançado.

O processamento motor começa com uma representação interna uma imagem do resultado desejado do movimento. Para uma organização harmônica do movimento, o sistema motor tem à sua disposição um fluxo contínuo de informações advindas do ambiente e que informam também a posição e a orientação das partes do corpo no espaço. A organização do movimento é hierárquica e pode-se dizer que ocorre em três níveis básicos de controle: medula espinhal, sistemas descendentes do tronco encefálico e áreas motoras do córtex cerebral (Kandel et al., 2000).

A medula espinhal é o nível mais inferior da hierarquia e contém circuitos neuronais mediadores de grande variedade de padrões motores; em última instância todos os sinais do controle motor convergem para os neurônios motores medulares, os quais inervam o músculo esquelético. 0 nível seguinte, representado pelo tronco encefálico, contém dois sistemas neuronais paralelos: o lateral, controlador dos músculos distais dos membros (importantes para o movimento) e o medial, que controla os músculos do 
tronco e os músculos proximais dos membros e influencia, desse modo, a postura. O mais alto nível de controle é formado por áreas do córtex motor, especialmente pelo córtex motor primário, a área pré-motora e a área motora suplementar. Além desses três níveis, duas outras partes do encéfalo também contribuem para a regulação da função motora: o cerebelo e os núcleos da base (Kandel et al., 1998).

Dada toda esta complexidade, uma disfunção em qualquer parte desse circuito pode gerar uma desordem do movimento. As doenças neurológicas causam diversas manifestações motoras, como fraqueza, bradicinesia, tremor ou ataxia.

A apraxia também é uma desordem dos movimentos aprendidos, resultante de uma disfunção neurológica. Segundo Heilman e Rothi (1985) a definição das apraxias é mais difícil até mesmo que a definição de afasia, uma vez que as características dos movimentos e, por conseguinte suas alterações, não são adequadamente descritas. Para um paciente apráxico a realização de uma tarefa motora, até então rotineira, pode tornar-se difícil ou mesmo impossível (van Heugten et al., 1999). Contudo a apraxia não é resultado de fraqueza, alteração sensitiva, ataxia, acinesia, bradicinesia, hipometria, ou alteração na performance motora devido a tremor, distonia, coréia, balismo, atetose ou mioclonia (Rothi et al., 1991). Esta pode ser definida como uma falha em produzir o movimento correto em resposta a um comando verbal, falha em imitar corretamente um movimento realizado pelo examinador, falha em realizar um movimento corretamente em resposta a um objeto observado ou ainda falha em manipular um objeto 
adequadamente (Leiguarda, 2000). Segundo Barbieri e De Renzi (1988) apraxia é uma disfunção que se manifesta pela dificuldade (ou incapacidade) em selecionar e organizar as inervações motoras necessárias para executar uma ação, independente das características desta ou mesmo do membro usado para realizar a ação. Pacientes apráxicos conseguem contrair seus músculos e se mover. Entretanto eles selecionam os padrões de inervação incorretos, levando um ato motor a ser substituído por outro, muitas vezes inapropriado, fragmentado, deslocado no tempo e no espaço (Prasmstaller e Marsden, 1996).

Em 1900, Hugo Karl Liepmann¹, um jovem neurologista alemão, (apud Rothi e Heilman, 1996) foi o primeiro a estudar a apraxia de forma sistemática. Ele descreveu um paciente com apraxia de membros superiores, sendo o direito muito mais acometido do que o esquerdo. A partir do estudo deste caso, Liepmann propôs que um prejuízo na execução motora poderia existir com a compreensão intacta da linguagem. Em 1907, Liepmann e Maas $^{2}$ (apud Watson e Heilman, 1983) descreveram um segundo paciente que apresentava afasia transcortical motora com apraxia do membro superior esquerdo e agrafia, com hemiplegia à direita. $\mathrm{O}$ membro superior esquerdo apráxico não melhorava o desempenho com imitação ou uso real do objeto. A descrição clínica brilhante e detalhada de Liepmann e seus trabalhos posteriores formaram a base para todos os modelos neuropsicológicos de apraxia (Pramstaller e Marsden, 1996).

\footnotetext{
${ }^{1}$ Das Krankheitsbild der Apraxie (motor asymbolie). Monatschrif für Psychiatrie und Neurologie.1900; 8,15-44.

${ }^{2}$ Liepmann H, Mass O. Fall von linksseitiger Agraphie und apraxie bei rechtsseitiger Laehmung. $J$ Psychol Neurol. 1907;10:214-27.
} 
Sabe-se que a apraxia pode ser seqüela de uma lesão hemisférica estável (Goldenberg, 1995; Goldenberg e Strauss 2002; Heath et al., 2001; Heilman et al., 1997), lesões no corpo caloso espontâneas ou cirúrgicas (Lausberg et al., 2003; Goldenberg et al., 2001; Graff Radford et al., 1987; Watson e Heilman 1983), mas também está presente em algumas doenças degenerativas como a doença de Alzheimer (Travniczek-Marter et al., 1991; Benke, 1993; Yesavage et al., 1993), doença de Parkinson, degeneração córtico-basal e a paralisia supranuclear progressiva (Leiguarda et al., 1997; e Pharr et al., 2001).

Dentre os pacientes com lesão vascular, a prevalência de apraxia varia conforme os estudos. Donkervoort et al. (2000) observaram que um terço dos pacientes com lesão em hemisfério esquerdo decorrente de doença vascular tem apraxia. Já Pedersren et al. (2001) mencionam que a apraxia aparece com uma freqüência de $10 \%$ entre os pacientes com acidente vascular encefálico no hemisfério esquerdo e 4\%, entre aqueles com lesão à direita.

A apraxia ideomotora (AIM) pode ser definida como um distúrbio na organização temporal, espacial e seqüencial de um gesto (Rothi et al., 1991). Na doença de Alzheimer (DA) a AIM pode estar presente em pacientes nos estágios moderado ou avançado da doença (TravniczekMarter et al., 1991) e até em um terço dos pacientes com DA leve (Della Sala et al., 1988; Benke,1993). Yesavage et al. (1993), em um estudo longitudinal, acompanharam pacientes de dois centros diferentes durante três anos avaliando a progressão do declínio cognitivo e a presença de 
apraxia nos pacientes. O autor afirma que a presença de apraxia no início da doença, ou o surgimento dessa durante a evolução da mesma, leva a uma progressão mais rápida do declínio cognitivo quando esses pacientes são comparados com aqueles que nunca desenvolveram apraxia. Blondel et al. (2001) afirma que a apraxia encontrada em pacientes com DA é relativamente independente da gravidade da demência. As desordens dos movimentos aprendidos nos pacientes com DA são qualitativamente similares às encontradas nos pacientes com lesões hemisféricas.

\subsection{A elaboração e a execução dos gestos}

Para realizarmos um ato motor previamente aprendido, cada parte do corpo em particular deve ser colocada em certas posições espaciais em uma seqüência temporal específica. Estas posições no espaço dependem não apenas da natureza do ato, mas também da posição e tamanho de um objeto externo com o qual os segmentos do corpo devem interagir (se houver um objeto no ato a ser realizado). Esses atos aprendidos também requerem mudanças ordenadas na posição espacial das partes do corpo ao longo do tempo (Heilman e Rothi, 1985).

O movimento voluntário pode ter um significado (isto é, gesto) ou ser sem sentido. Um gesto pode ser definido como o resultado de uma integração complexa de uma idéia do movimento e sua execução no tempo e no espaço. Gestos são padrões de comportamento aprendidos, enquanto movimentos sem sentido também podem ser aprendidos, mas, diferentemente dos gestos, não estão relacionados com a manipulação de 
objetos ou comunicação simbólica. Movimentos transitivos expressam uma ação de um sujeito sobre um objeto; movimentos intransitivos expressam uma ação que não é realizada com um objeto e pode ter ou não um significado (Mozaz, 1992).

Os modelos teóricos propostos para explicar as funções práxicas possuem dois componentes: um sistema conceitual que inclui 0 conhecimento do uso de instrumentos e funções mecânicas e um sistema de produção que inclui a informação contida nos programas de atos motores e sua tradução em bons desempenhos de tarefas motoras (Carrilo, 1996).

Para Hugo Liepmann³ (1908) (apud Rothi e Heilman, 1996) a idéia da ação, ou fórmula do movimento contendo as figuras têmporo-espaciais, estaria armazenada no lobo parietal esquerdo em uma área por ele denominada de sensoriomotorium. Para realizar um movimento o planejamento têmporo-espacial deveria ser recuperado e associado, através de conexões corticais, com os padrões de inervação já armazenados. Quando o movimento fosse realizado pelo membro superior esquerdo, a informação seria transmitida do sensoriomotorium esquerdo para o direito através do corpo caloso, para então ativar o córtex motor direito (Figura 1). O autor propôs a existência de tipos diferentes de alterações práxicas. Um aconteceria quando houvesse uma interrupção do planejamento têmporoespacial ou da ativação desse. Nesse caso seria impossível construir a idéia do movimento. $\mathrm{O}$ autor denominou esse déficit de apraxia ideatória (AI). Já quando os planejamentos estivessem intactos, mas não pudessem mais

\footnotetext{
${ }^{3}$ Drei Aufsätze aus dem Apraxiegebiet. Berlim: Karger. 1908.
} 
guiar os engramas os quais implementam os atos motores, aconteceria a apraxia ideomotora (AIM).

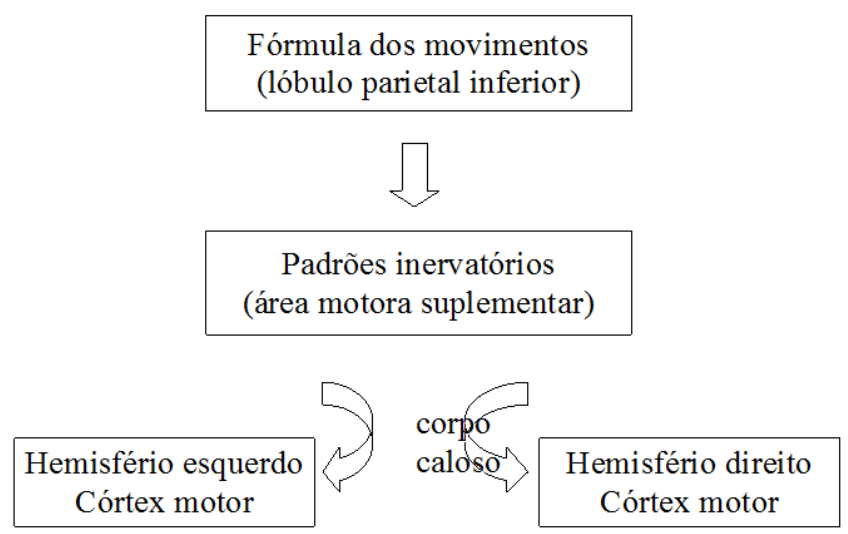

Figura 1 Esquema proposto por Liepmann para explicar a elaboração de gestos.

Pouco mais de meio século se passou até que Geschwind (1965), baseado nas idéias de Liepmann, propusesse outro modelo. O autor acreditava que o hemisfério esquerdo de indivíduos destros era responsável pelo controle dos movimentos aprendidos de ambas as mãos. Ele propôs um circuito neural para a explicar os gestos, muito semelhante ao utilizado para a linguagem. Nesse modelo, para a pantomima ser realizada ao comando verbal a ordem deveria dirigir-se do giro de Heschl para a porção pósterosuperior do lobo temporal (área de Wernicke). Subseqüentemente a informação iria para o 
córtex motor de associação, onde os movimentos seriam programados e, por fim, para a área motora primária, a fim de que o movimento fosse realizado com

o membro superior direito. Para os movimentos realizados com membro superior esquerdo a informação atingiria o córtex pré-motor direito através do corpo caloso. Assim, lesões do giro supramarginal ou do fascículo arqueado resultariam em apraxia pelo fato de desconectarem as áreas da linguagem das áreas de associação motoras. Os pacientes seriam capazes de compreender o comando, porém não seriam capazes de executar os gestos solicitados nessa modalidade. Todavia, segundo o modelo, eles seriam capazes de imitar gestos. Contudo muitos pacientes não o são. Para explicar isso o autor propôs que as fibras advindas do córtex de associação visual e que se dirigem para o córtex pré-motor, estão localizadas na porção anterior do fascículo arqueado, logo o fascículo arqueado do hemisfério esquerdo seria dominante para essas conexões vísuo-motoras (Figura 2).

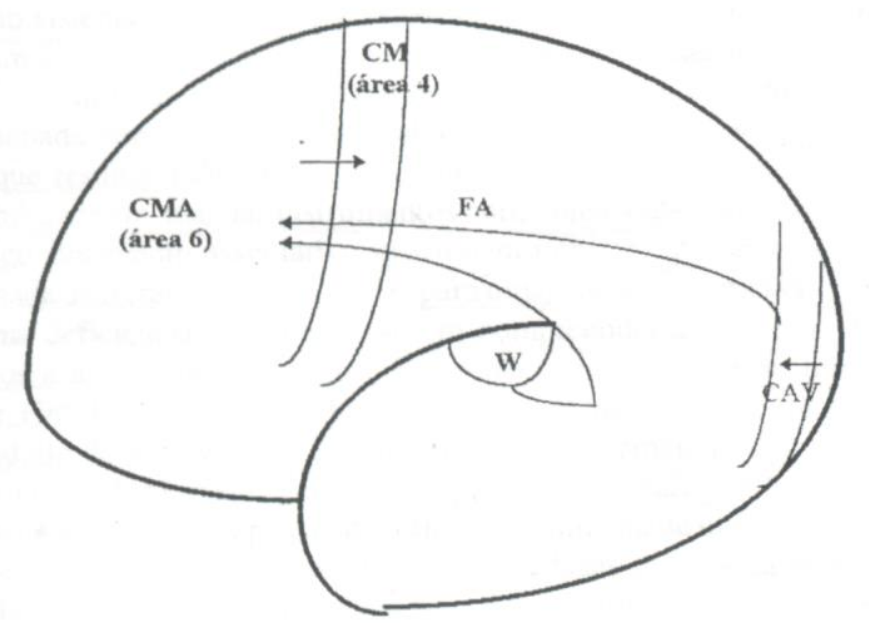

Figura 2 - Esquema proposto por Geschwind para explicar as alterações práxicas 
Em 1982, Heilman et al. sugeriram a existência de diferentes tipos de apraxia ideomotora (AIM), baseados na observação da capacidade dos pacientes de reconhecer gestos. Os autores propuseram a existência de pelo menos dois tipos de AIM. Um deles seria decorrente de lesão do giro supramarginal ou angular. $O$ paciente teria um mau desempenho ao comando verbal e imitação, assim como não conseguiria discriminar gestos bem de mal realizados. O outro tipo ocorreria em lesões anteriores ao giro supramarginal, com desconexão dos engramas motores vísuo-cinéticos das áreas pré-motoras. Este grupo também apresentaria dificuldade em realizar gestos ao comando verbal, e até em imitar gestos, porém seria capaz de distinguir entre gestos bem realizados e gestos mal realizados.

Rothi et. al. (1991) consideram que esses achados estão de acordo com a proposta de Liepmann de que existiriam "fórmulas de movimento" ou memórias que guiam os movimentos aprendidos das duas mãos. Quando essas memórias são destruídas, como nas lesões do lobo parietal esquerdo, haveria uma incapacidade de produzir ou discriminar gestos. Em contraste, quando essas memórias motoras não podem mais interagir com a parte do cérebro responsável pela geração dos chamados "padrões de inervação" ou os padrões de inervação não conseguem mais ganhar acesso às áreas motoras para que esses sejam executados, o resultado é a apraxia sem dificuldade de discriminação do gesto.

Estes mesmos autores (Rothi et al., 1991) também propuseram um modelo interessante, e amplamente aceito hoje em dia, do funcionamento do processo de produção de gestos. Eles separaram funcionalmente o 
processamento da fórmula de movimento, que lida com o significado da ação (chamada por eles de semântica de ação), daquele que lida com os atributos físicos da ação (denominada "léxico de ação").

Segundo eles haveria uma vantagem processual para a recuperação de gestos já aprendidos, para os quais já houvesse um programa previamente construído. Em linguagem o termo "léxico" pode ser definido como a parte do sistema lingüístico que fornece uma vantagem de processamento de palavras com as quais o usuário já possua experiência prévia. Os autores propuseram o termo "léxico de ação" para definir aqueles gestos para os quais o sujeito tivesse alguma experiência prévia.

O léxico de ação possuiria uma porta de entrada para captação da informação (INPUT) e uma via de saída da informação processada (OUTPUT). Os assim chamados "modelos de inervação" seriam os padrões de ativação neural dos sistemas motores necessários para 0 bom desempenho de determinado ato.

Baseado em casos nos quais a recepção do gesto estaria preservada e em que a performance nos testes sob comando verbal seria bem melhor do que nas provas de imitação, foi adicionada ao modelo uma alça na qual a linguagem ganharia acesso ao OUTPUT do léxico de ação sem ser processada pelo INPUT lexical. Assim, problemas tanto na realização de gestos ao comando verbal quanto à imitação seriam resultado de uma disfunção no ou após o acesso ao OUTPUT do léxico de ação. Também devido a relatos de disfunções específicas apresentadas por pacientes, os autores adicionaram outras alças ao modelo (Figura 3). Essas seriam 
capazes de elucidar não só as alterações na realização dos gestos dependendo da modalidade (verbal, visual ou tátil) utilizada para solicitar a execução da pantomima, mas também o porquê de alguns pacientes serem capazes de imitar gestos que não são capazes de compreender ou discriminar (via não lexical). A ação conteria, portanto, basicamente duas partes, o conhecimento conceitual e a informação estrutural contida nos programas motores. Como já citado acima o conhecimento conceitual estaria relacionado não só à ação, mas também aos objetos e ferramentas necessários e/ou empregados na ação, consistindo na chamada memória semântica de ação.

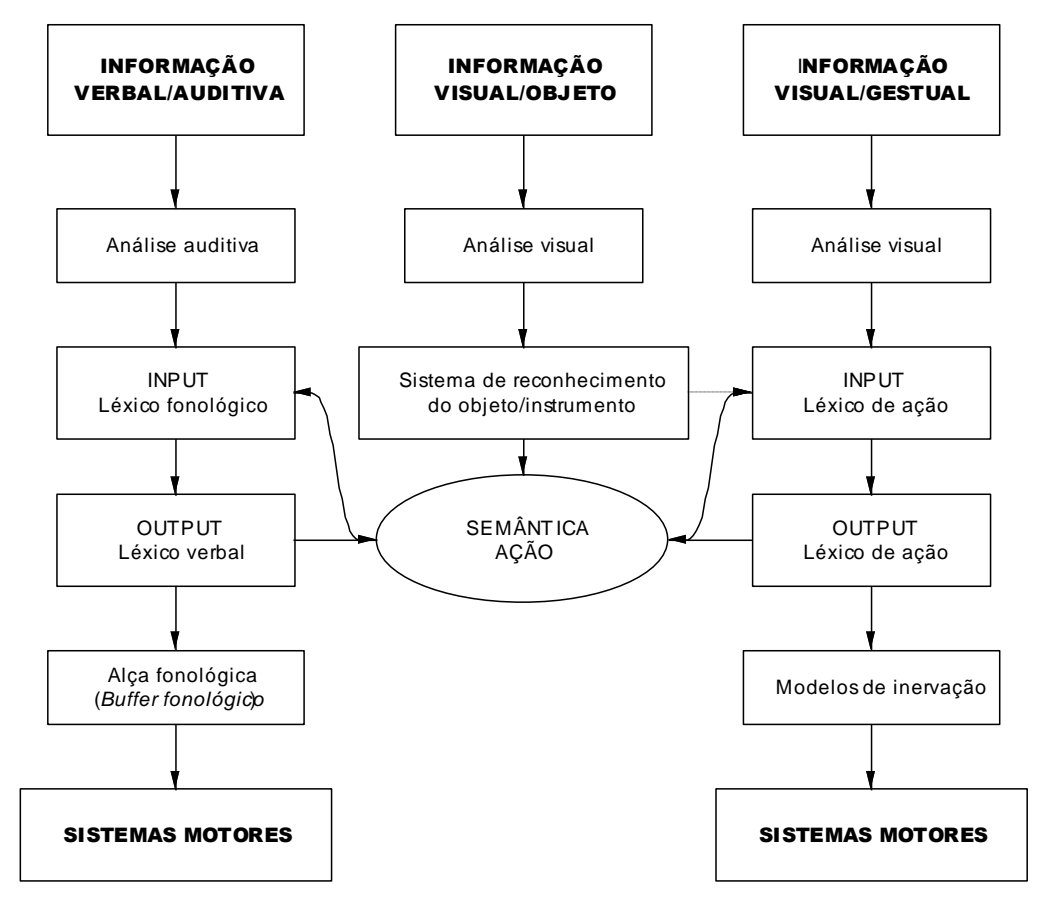
gestos

Figura 3 - Modelo do funcionamento do processo de produção de proposto por Rothi et al. 1991 
Assim a síndrome conhecida com AIM seria resultado de mau funcionamento do sistema executivo. Já um déficit no sistema conceitual envolveria dificuldades em reconhecer as vantagens mecânicas oferecidas pelas ferramentas e as necessidades mecânicas dentro de uma ação.

Hoje é amplamente aceito que a Al e a AIM são independentes uma da outra e resultam de disfunções de mecanismos diferentes, porém podem ocorrer ao mesmo tempo no mesmo paciente (Mozaz, 1992; De Renzi e Luchelli 1988; Benke 1993; Dumond e Ska 2000; Rapcsak 1998; Derouesné et al., 2000). A AIM é resultado de lesão no sistema de execução e a Al no sistema conceitual (Heilman e Rothi, 1985; Leiguarda e Marsden 2000; van Heugten et al., 1999). Os pacientes com AIM apresentariam durante a execução dos gestos erros principalmente de produção, como por exemplo, erros de orientação espacial e temporal. Já os pacientes com Al apresentariam principalmente erros de conteúdo (Heilman e Rothi, 1985; Ochipa et al., 1989).

Pacientes com Al também apresentam dificuldades na hora de selecionar objetos ou ferramentas, causadas por uma incapacidade de entender a natureza mecânica de problemas e as vantagens mecânicas que determinadas ferramentas podem trazer, levando a uma incapacidade de resolver problemas mecânicos e também de desenvolver ferramentas para solucionar esses problemas (Ochipa et al., 1992).

Ao estudar a capacidade de pacientes com DA em reconhecer e produzir pantomimas, Benke (1993) coloca que os mesmos apresentam sinais marcantes de apraxia conceitual no uso de objetos, nas pantomimas, 
com o déficit se manifestando até mesmo no nível do reconhecimento. A imitação de movimentos sem sentido, que envolviam posicionamento da mão e uso de duas mãos, também se mostrou gravemente afetada nos pacientes com DA, evidenciando um defeito no componente estrutural das praxias.

Halsband et al., (2001) estudaram em 26 pacientes com lesões cerebrais não progressivas a capacidade de produzir e reconhecer gestos. Os sujeitos apresentaram um déficit bem mais pronunciado na produção dos gestos quando comparados ao reconhecimento, reforçando a idéia de que existam dois sistemas distintos quando se pensa na realização de um ato motor.

Dumont e Ska (2000) utilizaram uma tarefa de reconhecimento e de produção de gestos na avaliação de pacientes com DA. Todos os pacientes que foram mal na tarefa de compreender pantomimas também foram na execução destas, enquanto o padrão inverso não foi observado. Comparações quantitativas sugerem que os déficits nos dois domínios não são correlacionados.

Derouesné et al. (2000) descreveram as desordens práxicas em pacientes com DA leve e moderada usando o modelo neuropsicológico desenvolvido por Rothi et al. (1991). Para os autores, a gravidade das alterações práxicas não está associada com o sexo, a idade ou o nível de escolaridade. A natureza dos movimentos simbólicos ou sem sentido, transitivo ou intransitivo, representa um papel menor e o ponto chave do déficit é a incapacidade do paciente de fazer escolhas deliberadas entre 0 
seu repertório de inervações motoras, caso não seja assistido por uma série de circunstâncias que possam trazer alguma facilitação. A relação ente apraxias e dificuldades nas AVDs parece estar relacionada mais a transtornos do sistema conceitual do que à gravidade global dos déficits cognitivos ou a problemas com a compreensão verbal.

$\mathrm{Na}$ amostra de Rapcsak et al. (1989) todos os indivíduos apresentavam algum grau de AIM e esta estava associada à Al. Por outro lado, Ochipa et al. (1992) mostraram que todos os pacientes com DA apresentavam pior desempenho em tarefas conceituais quando comparado a controles. Esses déficits ocorreram mesmo na ausência de AIM. Entretanto, os autores usaram critérios diferentes para definir e também para medir a Al. Para Rapcsak et al. (1989) o déficit em realizar tarefas em seqüência significa que o indivíduo apresenta uma dificuldade na concepção do gesto. Já para Ochipa et al. (1992), uma desordem na associação entre objetos, ferramentas e ações mecânicas que devem ser alvo de ambos, é o que caracteriza a $\mathrm{Al}$, que os autores preferem chamar de apraxia conceitual justamente para não confundir com erros de seqüência.

Classicamente na procura por transtornos práxicos solicita-se ao sujeito que realize gestos ao comando verbal, à imitação e de fato utilizando o objeto. Os gestos solicitados podem ser pantomimas de uso de objetos e gestos intransitivos com ou sem nenhum significado. Também se solicita que o sujeito realize pantomimas de uso de objetos após ver o objeto, sem tocálo. Para avaliar o sistema conceitual utiliza-se a realização de tarefas motoras em seqüência (Rapcsak, 1989 e De Renzi e Lucchelli, 1988). A 
classificação de um paciente como apráxico ou não depende da avaliação dos erros cometidos pelos pacientes.

De Renzi (1982) aponta o efeito da modalidade de apresentação como um elemento crítico em qualquer definição operacional de apraxia. O estudo do autor mostrou um efeito da modalidade na investigação da apraxia em pacientes com seqüela de doença encéfalo-vascular.

O estágio de execução é idêntico para os gestos com e sem sentido. A imitação de gestos é tida como o teste mais direto da integridade do estágio de execução (Goldenberg e Hagmann, 1997). A afirmação de que as desordens de imitação afetam principalmente os gestos com e sem sentido é endossada pelos estudos que não encontraram diferenças estatisticamente significantes entre a imitação de gestos com e sem sentido em grupos de pacientes com lesão em hemisfério esquerdo (De Renzi et al., 1980).

Para Heilman e Rothi (1985) existem quatro formas de testar a performance práxica do indivíduo: gesto ao comando, imitação de um gesto, uso real do objeto e imitação do examinador usando um objeto. $O$ movimento escolhido pode ser ainda um gesto convencional ou uma pantomima. Também se deve testar a capacidade de compreensão do movimento. Isso deve ser feito pedindo ao paciente para descrever o que foi dito que fizesse, solicitando ao paciente que aponte para o objeto, dentre uma gama de objetos, que deve ser usado para uma ação específica e a capacidade do indivíduo de discriminar um gesto bem realizado de um gesto mal realizado. O examinador deve determinar se um paciente que esteja cometendo erros de execução pode selecionar um gesto entre vários 
apresentados e/ou diferenciar um gesto bem executado de um mal executado.

Os diferentes métodos de testagem podem desencadear tanto os componentes ideatórios quanto os executivos, independente da natureza do gesto.

A Al não está necessariamente associada a ações complexas. Quando um indivíduo é solicitado a realizar um gesto, se o componente ideatório estiver intacto a performance dependerá do componente executivo. Então quando a compreensão verbal está intacta, a queda no desempenho pode não ser suficiente para determinar se a dificuldade ocorre no componente executivo ou em ambos e a análise das respostas em diversos modos de testagem é essencial. A realização incorreta de um gesto sob comando verbal, não é capaz de nos dizer se o problema ocorre na elaboração ou na execução do mesmo. A imitação afeta apenas o componente executivo, uma vez que a idéia do plano da ação é fornecida pelo examinador. Uma imitação incorreta pode ser consistente com comprometimento executivo, apesar da preservação do componente ideatório do gesto. Pacientes que cometem erro na imitação de posturas da mão e dos dedos também cometem erros quando Ihes é solicitado que façam a ligação entre figuras similares de posturas dos dedos e da mão (Goldenberg e Hagmann, 1998) ou repliquem posturas da mão em um manequim (Goldenberg, 1996). Como as demandas motoras de apontar para fotografias apropriadas ou a manipulação de um manequim são fundamentalmente diferentes daquela de imitar o gesto, a desordem subjacente parece residir em estágios do processamento 
cognitivo que precedem a execução motora. Uma imitação adequada, portanto, indica a preservação do componente executivo, mas não necessariamente da idéia do movimento. È necessário nesses casos averiguar se o paciente é capaz ou não de reconhecer os gestos. Independente do tipo de gesto ou de sua complexidade, é essencial apurar se o componente ideatório, o executivo ou ambos estão prejudicados. A análise apenas da falha em produzir gestos ao comando ou à imitação não pode mais ser considerado como um critério válido para classificar a apraxia em Al ou AIM. É muito importante que se faça uma análise das respostas nas diferentes tarefas avaliadas para certificar-se da presença de Al ou AIM (Mozaz, 1992).

A maioria dos testes de apraxia não discrimina entre o conhecimento motor estrutural e conceitual ou avalia apenas os atos motores simbólicos ou relacionados a objeto. Isso acontece não somente quando se estudam indivíduos com lesão em hemisfério esquerdo, mas também na investigação da DA (Benke, 1993).

Assumindo o modelo proposto por Rothi et al. (1991) como o mais completo para explicar os sistemas envolvidos na produção práxica, o funcionamento desses sistemas poderia apenas ser avaliado através da comparação da performance dos pacientes em várias tarefas. O sistema conceitual deve ser avaliado por meio de tarefas nas quais não é necessária a implementação de gestos, para prevenir a interferência do sistema de produção. Essas tarefas seriam, por exemplo, de reconhecimento do uso correto de um objeto e a associação entre um objeto e o gesto. A avaliação 
do sistema de produção precisa levar em consideração os escores de imitação de gestos transitivos e intransitivos (via lexical) e os movimentos sem sentido (via não lexical), para prevenir a interferência do sistema conceitual e também comparar a performance dos gestos ao comando verbal e à imitação para avaliar o acesso verbal e visual ao sistema semântico (Derouesné et al., 2000).

O fato de aspectos diferentes do sistema práxico estarem comprometidos em pacientes demenciados justifica a aplicação de testes que avaliem praxias na rotina de avaliações clinicas desse grupo de pacientes, não apenas pelo diagnóstico mas também para definição do prognóstico, uma vez que pacientes que desenvolvem apraxia podem apresentar declínio mais rápido do aqueles que não o fazem (Taylor, 1994; Dobigny-Roman, 1998). Um teste abrangente de apraxia pode ser crítico também na diferenciação entre degeneração córtico-basal e paralisia supranuclear progressiva (Pharr, 2001).

Dessa forma, podemos concluir que uma avaliação das praxias deveria incluir, entre outros componentes, uma avaliação da produção de gestos sob comando verbal e imitação e também uma avaliação da capacidade de reconhecimento de gestos. Para isso é importante que existam instrumentos padronizados, os quais possam ser úteis no diagnóstico, avaliando a presença ou ausência de distúrbios práxicos, bem como no seguimento dos pacientes submetidos à reabilitação. 


\subsection{Instrumentos de avaliação de praxias de membros.}

Medir ou mais especificamente diagnosticar apraxia é difícil e os testes padronizados são escassos. A maioria dos procedimentos utilizados para os testes foi desenvolvida para elaborar um modelo teórico e o desenvolvimento de algumas hipóteses e são aplicados em estudos empíricos. Até o momento, nenhum sistema de escore para apraxia foi aceito completamente devido à incerteza sobre o que e como medir. Os clínicos que tentam diagnosticar apraxia o fazem baseados na experiência pessoal, na impressão clínica ou na intuição (van Heugten et al., 1999).

De Renzi et al. (1980) elaboraram um teste que continha 24 gestos classificados em três categorias: gestos que envolviam toda a mão ou apenas alguns dedos, gestos nos quais o sujeito deveria manter uma posição ou realizar uma seqüência de atos e gestos simbólicos e não simbólicos. Era solicitado ao sujeito que realizasse o gesto assim que o examinador terminasse a apresentação, ou seja o sujeito deveria evocar a memória do gesto solicitado. A cada item era atribuído um valor de 3 a 0 dependendo se a performance correta acontecesse na primeira, segunda ou terceira tentativa ou se o sujeito falhasse. O teste foi realizado em indivíduos com lesões vasculares, tumorais e traumáticas. Todavia, por ser um teste longo e que necessita da memorização do gesto a ser realizado, não é um teste indicado para a avaliação de pacientes com DA, além do que prevê apenas a realização de gestos à imitação.

Pensando principalmente nesse último grupo de pacientes, DobignyRoman et al. (1998) criaram um protocolo (The Ideomotor Apraxia Test) com 
o propósito de ser um teste rápido e de fácil realização, dada a dificuldade de concentração desses pacientes e o enorme número de testes neuropsicológicos aos quais estes são submetidos. O teste deveria não só identificar a presença da AIM, como também quantificá-la. Para os autores a dificuldade à realização dos gestos sem sentido é uma das primeiras a se manifestar na DA. Os autores avaliaram 55 pacientes, juntamente com 26 controles, em um teste que contém 10 gestos sem sentido. O teste mostrou boa sensibilidade e especificidade, bem como validade e reprodutibilidade. A idade mostrou ter um efeito na qualidade das pantomimas, especificamente com relação à utilização de parte do corpo como objeto, que foi uma resposta freqüentemente observada nos 26 idosos saudáveis. Alguns movimentos que usam objetos reais também estão alterados nos idosos. Entretanto, este protocolo inclui apenas a imitação de gestos e não avalia a execução de gestos bimanuais sem significado e nem unimanuais com significado.

Kokmen et al. (1998) elaboraram uma bateria de avaliação de praxias com 55 itens divididos em sete sub-partes e aplicaram-na a duas populações culturalmente diferentes (turcos e norte-americanos) com doenças neurológicas diferentes. Os autores não encontraram diferenças significativas no desempenho dos pacientes nos dois países. Os pacientes com DA mostraram pior desempenho nos testes quando comparados a controles, mas não quando comparados com pacientes com outras doenças degenerativas. O teste também mostrou-se rápido e de fácil aplicação. Todavia, apesar de resultados semelhantes, os grupos não eram 
homogêneos com relação ao número de indivíduos com os diferentes diagnósticos: o grupo americano com DA, por exemplo, era formado por 16 pacientes, enquanto o turco continha apenas dois. Além disso, os gestos eram realizados somente ao comando verbal e não à imitação, o que não seria aplicável a pacientes com alterações de linguagem.

van Heugten et al. (1999) desenvolveram uma bateria com o objetivo de diagnosticar e diferenciar a AIM da Al. A bateria era composta de dois sub-testes: demonstração do uso de objetos em três modalidades (visual, verbal e tátil) e imitação de gestos. O primeiro foi elaborado com a intenção de detectar a presença de Al e o segundo, de AIM. Os objetos apresentados em uma modalidade não eram os mesmos apresentados na outra e os seis gestos a serem imitados eram todos intransitivos, exceto o de assoprar uma vela. O teste foi avaliado em 44 pacientes com diagnóstico de doença encéfalo-vascular com apraxia, 35 pacientes com o mesmo diagnóstico mas sem apraxia (os autores colocam apenas que os sujeitos foram classificados como apráxicos ou não baseado na avaliação clínica) e 50 idosos controles. O valor diagnóstico foi expresso em termos da sensibilidade, especificidade e valor preditivo do teste. A análise dos dados mostrou que o diagnóstico de apraxia seria possível quando tomado por base o escore total, ou seja, os dois sub-testes juntos mediriam o mesmo aspecto. O teste seria capaz, então, apenas de separar o paciente em apráxico ou não.

Mozaz et al. (2002), com o objetivo desenvolver um teste que não dependesse da compreensão dos comandos verbais e não utilizasse pantomimas ou produção de gestos, criaram o "Postural Knowlodge Test". O 
teste contém cartões que mostram uma pessoa realizando a ação. Tanto gestos transitivos quanto convencionais são representados. O sujeito deve escolher o gesto corretamente realizado entre três dos quais somente um é correto. Os autores aplicaram o teste em 20 sujeitos idosos normais, os quais apresentaram problemas maiores na seleção de posturas corretas para os movimentos transitivos do que para os intransitivos, indicando que a representação dos gestos intransitivos está armazenada ou é ativada de maneira diferente do que a de pantomimas transitivas.

Entretanto, esses dois últimos testes descritos não levam em consideração um dos dois sistemas envolvidos na elaboração dos gestos, e talvez a realização de ambos juntos fizesse com que um suprisse a falha do outro. Soma-se a isso o fato do segundo teste estar em processo de validação.

$\mathrm{Na}$ literatura existem ainda diversos outros testes descritos para avaliação de apraxia. Estes podem ser agrupados em duas categorias principais: a) os que usam o comando verbal e a imitação (ou apenas a imitação) e b) aqueles que usam a apresentação do objeto em três modalidades (verbal, visual e tátil). Todos eles dependem do julgamento dos erros cometidos durante a realização do movimento, e descrições e categorias de erros são bem estabelecidas na literatura (Mozaz, 1992; Leiguarda, 2000; Carrilho, 1996), porém informações sobre a confiabilidade e a validade destes testes são raras (Butler, 2002).

Butler (2002) aplicou quatro protocolos diferentes de avaliação de apraxia em 30 pacientes com lesão unilateral do hemisfério esquerdo. 0 
autor encontrou uma falta de correlação entre os testes. Todos eles foram capazes de identificar os pacientes apráxicos na amostra, todavia cada teste identificava um aspecto diferente da condição. O autor coloca que a preocupação com estudos de confiabilidade e validade dos protocolos de avaliação deve ser imediata, visto que em muito ajudará no debate sobre as apraxias, e que a falta de instrumentos padronizados utilizados nos estudos prejudica muito a análise dos resultados dos mesmos. Ele propõe que deve haver um consenso sobre a definição de apraxia e um esforço na busca da criação de um instrumento padrão-ouro para o diagnóstico e quantificação desta.

Tendo em vista justamente o modelo proposto por Rothi et al. (1991), Rock e Ska (1994) e Ska et al. (1997) criaram dois protocolos complementares para avaliar tanto o sistema conceitual quanto o sistema de produção de gestos. Para avaliar o sistema conceitual foi elaborado um vídeo subdividido em cinco provas diferentes nas quais os sujeitos devem distinguir gestos bem realizados de gestos mal realizados, associar corretamente gestos a objetos e nomear gestos, entre outras. O protocolo de avaliação da produção de gestos consiste na realização de gestos transitivos, convencionais e sem sentido tanto ao comando verbal, à imitação e após observar a foto do objeto.

Como todos os testes neuropsicológicos a avaliação das praxias pode ser fortemente influenciada pela escolaridade e parece também o ser pela idade. Levando em consideração esses fatos, pouquíssimos testes de apraxia têm sido validados para a população idosa (Dobigny-Roman, 1998). 
Com o passar da idade algumas alterações motoras são evidentes, tais como, declínio da força, do equilíbrio e da marcha (Schummay-Cook e Woollacott, 2003), porém não há nenhuma descrição de como o envelhecimento influencia o reconhecimento de gestos e muito pouco sobre como afeta a produção.

Peigneux et al. (1999) avaliaram a influência da idade e da escolaridade na ocorrência de erros do tipo "parte do corpo como objeto" (PCO) em indivíduos normais e encontraram um efeito significante da idade e do nível educacional na produção de erros dessa natureza. Foi observado que houve um efeito significante da idade e do nível de escolaridade na produção de erros tipo PCO. Porém quando foi enfatizado que os gestos deveriam ser realizados como se eles estivessem segurando o objeto, não houve diferença entre jovens e idosos.

É necessário, portanto, criar um instrumento que seja capaz de identificar e quantificar a presença de apraxia tanto em indivíduos com lesões estáveis quanto naqueles com condições neurológicas de caráter progressivo levando em consideração as variáveis idade e a escolaridade. $\mathrm{Na}$ literatura nacional não existe descrição de nenhum protocolo de avaliação de gestos, bem como de avaliação de reconhecimento. Este último não é descrito nem na literatura estrangeira.

Dessa forma, a elaboração e, sobretudo, a padronização de instrumentos diagnósticos torna-se particularmente relevante, dada a sua ausência em estudos nacionais e mesmo sua relativa escassez - 
principalmente de testes de avaliação de reconhecimento - em estudos internacionais. 


\section{OBJETIVO}

\subsection{Objetivo Geral}

1. Avaliar o desempenho de indivíduos idosos saudáveis em um protocolo de produção e reconhecimento de gestos

\subsection{Objetivos Específicos}

1. Avaliar a influência das variáveis idade, escolaridade e sexo sobre o desempenho de indivíduos idosos saudáveis nos referidos protocolos.

2. Avaliar a confiabilidade intra e inter-examinador do protocolo de produção de gestos.

3. Avaliar a confiabilidade intra-examinador do protocolo de reconhecimento de gestos. 


\section{CASUÍSTICA E MÉTODOS}

\subsection{Sujeitos}

O desenho do estudo englobou a avaliação de 96 sujeitos com idade igual ou superior a 60 anos, sendo 48 do sexo feminino e 48 do sexo masculino. Estes foram divididos em dois grupos, conforme tabela abaixo (tabela 1): um grupo com idade entre 60 e 74 anos (grupo A) e o outro com idade igual ou superior a 75 anos (grupo B). Cada um dos grupos foi, ainda, dividido em quatro subgrupos de acordo com a escolaridade dos indivíduos. O primeiro subgrupo continha os sujeitos analfabetos, o segundo indivíduos com escolaridade de um a três anos, no terceiro grupo, os sujeitos com escolaridade de quatro a sete anos e no último, aqueles com escolaridade igual ou superior a oito anos. O subgrupo A continha 48 sujeitos e 0 subgrupo $B, 48$.

Tabela 1 - Distribuição dos sujeitos por categoria

\begin{tabular}{ccccc}
\hline Escolaridade & 0 & $1-3$ & $4-7$ & 8 ou mais \\
\hline $\begin{array}{c}\text { Grupo A } \\
\text { 60-74 anos }\end{array}$ & $12(6 \mathrm{~F} \mathrm{e} 6 \mathrm{M})$ & $12(6 \mathrm{~F} \mathrm{e} 6 \mathrm{M})$ & $12(6 \mathrm{~F} \mathrm{e} 6 \mathrm{M})$ & $12(6 \mathrm{~F} \mathrm{e} 6 \mathrm{M})$ \\
$\begin{array}{c}\text { Grupo B } \\
\geq \mathbf{7 5} \text { anos }\end{array}$ & $12(6 \mathrm{~F} \mathrm{e} 6 \mathrm{M})$ & $12(6 \mathrm{~F} \mathrm{e} 6 \mathrm{M})$ & $12(6 \mathrm{~F} \mathrm{e} 6 \mathrm{M})$ & $12(6 \mathrm{~F} \mathrm{e} 6 \mathrm{M})$ \\
\hline
\end{tabular}

Todos os sujeitos foram submetidos a avaliação cognitiva breve através do Mini-Exame do Estado Mental (MEEM; Folstein et al., 1975; Brucki et al., 2003), ao teste de fluência verbal semântica (Brucki, 2001) e ao 
teste de memória de figuras (Nitirini et al., 1994). Foram excluídos do estudo aqueles que apresentaram desempenho nos referidos testes abaixo do esperado para a população normal, a saber, pontuação no MEEM menor que 18 para os indivíduos analfabetos, 21 para aqueles que freqüentaram a escola de um a três anos, 24 para sujeitos com escolaridade de quatro a sete anos e 26 para aqueles com escolaridade superior a sete anos. No teste de fluência verbal, foram excluídos aqueles que nomearam menos que nove palavras, para os sujeitos analfabetos, onze para os indivíduos com escolaridade entre 1 e 3 anos, doze para 0 grupo de 4 a 7 anos de escolaridade e treze para os sujeitos com oito ou mais anos de escolaridade. Também foram excluídos os indivíduos que apresentaram pontuação menor ou igual a sete no item de memória tardia.

Não foram incluídos no estudo sujeitos que fizessem uso de drogas com ação sobre o sistema nervoso central bem como aqueles com história de abuso de álcool, além daqueles que apresentassem história de doença neurológica e/ou psiquiátrica prévia, conforme dados de história clínica.

Os indivíduos que participaram do estudo eram oriundos de programas de extensão para a terceira idade da Universidade de Taubaté (UNITAU), acompanhantes de pacientes da clínica de fisioterapia da UNITAU, bem como pacientes dos setores de ortopedia, gerontologia e disfunções respiratórias da mesma clínica, além de conhecidos dos autores.

Todos os sujeitos avaliados foram informados do objetivo do estudo e dos procedimentos a serem realizados, só fazendo parte do estudo aqueles que assinaram o termo de consentimento informado. 
O protocolo de pesquisa foi aprovado pela comissão de ética e pesquisa do Hospital das Clínicas da Faculdade de Medicina da Universidade de São Paulo e pelo comitê de ética e pesquisa da Universidade de Taubaté.

\subsection{Materiais}

Foram utilizados uma filmadora VHS, um aparelho de televisão, um vídeo cassete, uma fita VHS, uma ficha contendo dados da história clínica, medicamentos utilizados, um cronômetro, um computador e um protocolo de avaliação (apêndice I).

\subsection{Procedimento}

Os grupos foram avaliados da seguinte forma:

Identificação: idade, sexo, escolaridade, dominância manual, desempenho no MEEM, no teste de fluência verbal e memória de figuras.

Todos os sujeitos foram submetidos a dois protocolos de avaliação: um de produção de gestos sob comando verbal e sob imitação de movimento, e outro de reconhecimento dos gestos.

\subsubsection{Protocolo avaliação de produção de gestos (Ska et al., 1997)}

O protocolo se divide em três sessões: gestos que imitam a utilização de objetos, gestos convencionais e gestos sem significado. Em cada uma dessas categorias existiam gestos uni e bimanuais. A lista completa dos gestos encontra-se no apêndice II. 
Embora no protocolo original existisse a avaliação dos gestos mediante a apresentação de uma foto do objeto, optou-se pela não utilização dessa modalidade uma vez que poderia haver uma influência do sistema conceitual, já que o sujeito deveria reconhecer o objeto juntamente com todas as suas características.

Solicitava-se ao sujeito que realizasse o gesto de duas maneiras diferentes: ao comando verbal (CV) e à imitação (IM), contudo os gestos sem sentido eram realizados somente sob imitação. Os gestos unimanuais eram realizados com a mão de preferência do sujeito no comando verbal, e sempre com a mão direita no teste de imitação.

Os gestos eram apresentados na seguinte ordem: primeiro os gestos de utilização de objetos e gestos convencionais sob comando verbal e depois os gestos de utilização de objetos, gestos convencionais e os gestos sem sentido sob imitação. Os gestos unimanuais eram sempre realizados antes do bimanuais. A seqüência de gestos foi sempre mantida e é a mesma descrita no apêndice II.

Antes de se iniciar cada uma das provas (CV e IM), era dado como exemplo ao sujeito o ato de escovar os dentes. Era dito ao sujeito "Vou pedir para o(a) sr.(sra.), por favor, imitar alguns gestos que nós fazemos no dia a dia, como, por exemplo, escovar os dentes. $\mathrm{O}(\mathrm{A})$ sr.(sra.) vai fazer de conta que esta segurando o objeto, e depois vai fazer o gesto". Então o examinador solicitava ao sujeito que mostrasse o gesto. Quando o examinador julgava que $\mathrm{o}$ sujeito havia entendido começava-se a administração das provas sob CV. Nas provas de imitação dizia-se ao sujeito 
"agora eu vou realizar um gesto, o(a) sr.(sra.) deverá observar e quando eu acabar o(a) sr.(sra.) deverá fazê-lo da mesma forma. Preste atenção por que se eu realizar o gesto com a mão esquerda, o(a) sr.(sra.) também deverá fazê-lo com a mão esquerda e caso eu realize com a mão direita o(a) sr.(sra.) deverá fazer também com a mão direita". Novamente o gesto de escovar o dente era o utilizado como exemplo.

Para cada um dos gestos de utilização de objetos e os convencionais, o sujeito que executasse de forma correta e com a forma da mão adequada recebia dois pontos (um para o movimento e um para a forma) para cada condição (comando verbal e imitação).

Durante a realização dos gestos sem significado eram consideradas a forma da mão e a posição desta com relação a outras partes do corpo. Cada um dos gestos recebia dois pontos. Portanto o escore total do protocolo é de 54 pontos, 20 pontos para a prova sob comando verbal (12 para gestos com objeto, e oito para gestos convencionais) e 34 para imitação (12 para gestos com objeto, oito para gestos convencionais e 14 para gestos sem sentido).

Os critérios para julgar se o gesto era corretamente executado ou não foram:

\section{Forma da mão (1 ponto)}

A forma do objeto deveria ser respeitada, isto é, era levada em consideração a forma que a mão assumia em relação ao objeto. Neste caso eram considerados erros: a assimilação (parte do corpo como objeto, parte da mão se desviava do objeto alvo, a mão não realizava o gesto 
correspondente ao objeto solicitado, ou não se posicionava de forma correta de acordo com o objeto. Exemplo: muito aberta ou muito fechada para segurar o copo, ou se o sujeito realizava o gesto segurando o objeto e por fim outros tipos de erros que não os descritos aqui.

Caso o sujeito realizasse de forma correta era dado um ponto para a mão (independente da mão utilizada) nas tarefas unimanuais e meio ponto para cada mão nas tarefas bimanuais. Caso ele falhasse marcava-se zero pontos para esse item.

\section{Movimento (1 ponto)}

O sujeito deveria reproduzir corretamente a seqüência do movimento, respeitando a relação da mão com o objeto, com a outra mão e com as partes do corpo. Eram considerados erros: omissão (o gesto se aproxima do gesto solicitado, mas parte do gesto é omitida), não reconhecimento, erro espacial (o gesto é executado em um plano espacial diferente do que deveria ser), a mão se apresenta em uma posição inversa do que deveria ser (por exemplo o sujeito mostra o dorso da mão quando deveria mostrar a palma). Caso o sujeito realizasse de forma correta os gestos ele recebia um ponto para a mão de preferência nos gestos unimanuais e meio ponto para cada mão nos gestos bimanuais. Caso um dos elementos desse critério não fosse atingindo, nenhum ponto era atribuído ao sujeito.

Logo, se o sujeito realizasse o gesto corretamente ele receberia dois pontos para cada gesto, caso cometesse algum erro em uma das partes acima descritas, mas a outra estivesse correta, recebia um ponto e se ambos os critérios não fossem atingidos receberia zero pontos. 


\subsubsection{2 Ánalise da confiabilidade}

Para avaliar a confiabilidade intra-examinador de todo o protocolo de produção de gestos foram selecionados 26 indivíduos da amostra inicial ao acaso. Esses foram reavaliados pelo mesmo examinador com intervalo de duas semanas entre a primeira e a segunda avaliação.

Um outro examinador, com experiência na área, examinou o os vídeos de 20 sujeitos contendo o desempenho desses indivíduos no teste de produção de gestos e atribuiu as respectivas notas. Esse procedimento visava avaliar, a confiabilidade inter-examinador para o teste de produção de gestos.

\subsubsection{Teste de reconhecimento dos gestos (Rock e Ska, 1994)}

Foi apresentado ao sujeito um filme no qual um indivíduo realizava alguns gestos. Este filme tem como objetivo avaliar o reconhecimento, a nomeação de gestos, a discriminação entre um gesto bem realizado e um gesto mal realizado e o reconhecimento da associação entre gestos transitivos e objetos. A lista completa dos gestos encontra-se no apêndice III.

O filme consiste de cinco provas diferentes e tem duração aproximada de quarenta minutos. Em todas elas para cada resposta correta era atribuído um ponto e para cada resposta errada nenhum ponto era atribuído. Todas as provas eram precedidas de exemplos. O examinador explicava a prova e logo em seguida apresentava os exemplos (esses são descritos também no 
apêndice III). Após certificar-se de que o sujeito compreendia o que deveria ser feito, a prova tinha início. Cada gesto era apresentado apenas uma vez.

\subsubsection{Primeira prova: Reconhecimento de gestos}

Na primeira prova eram apresentados para o sujeito gestos que imitam a utilização de objetos, gestos transitivos e gestos que não apresentam nenhum significado. $\mathrm{O}$ sujeito deveria reconhecer os gestos que tem algum significado. Era dito ao sujeito: "Nesta esta prova, você vai ver uma pessoa fazendo uma série de gestos. Entre esses gestos, alguns têm um significado (eles representam alguma coisa comum), como por exemplo, o uso de um objeto ou um gesto que possa transmitir uma mensagem a outra pessoa, como por exemplo bocejar. Os outros gestos não têm significado algum (eles não querem dizer nada). $\mathrm{O}(\mathrm{A})$ sr.(sra.) vai assistir aos gestos um de cada vez e depois de cada um vai me dizer se esse é um gesto que significa alguma coisa ou não." Nessa prova havia 32 gestos, dos quais 16 tinham significado (oito de utilização de objetos e oito gestos convencionais) e 16 sem significado (oito estáticos e oito dinâmicos), assim o escore máximo que o sujeito poderia alcançar seria 32 pontos.

\subsubsection{Segunda prova: Decisão gestual}

A segunda prova é subdividida em duas partes. Em ambas o indivíduo realiza um gesto duas vezes, uma de maneira correta e outra de maneira incorreta. O sujeito deveria identificar qual das duas maneiras seria a correta. Na primeira eram apresentados 12 gestos que imitam a utilização de objetos, dos quais seis contém erros de orientação e seis de preensão. A 
segunda parte contém seis gestos convencionais, dos quais 3 contém erros de forma e os demais, erro de orientação No primeira parte da prova era dito ao sujeito: "Nesta prova a pessoa vai fazer dois gestos que imitam o uso de um objeto. Os gestos serão apresentados dois a dois, primeiro um e depois o outro. $\mathrm{O}(\mathrm{A})$ sr.(sra.) deve olhar atentamente os dois gestos que a pessoa fizer e depois o(a) sr.(sra.) deve me dizer qual dois foi o certo: o primeiro ou o segundo." Na segunda, o indivíduo recebia a seguinte ordem: "Nesta segunda parte, a pessoa faz gestos convencionais, que querem passar alguma mensagem, mas que não utilizam nenhum objeto. Olhe atentamente os dois gestos, que representam a mesma ação, e depois você o(a) sr.(sra.) me fala qual dos dois foi feito de maneira correta: o primeiro ou o segundo".

\subsubsection{Terceira prova: Julgamento de similaridade}

$\mathrm{Na}$ terceira prova eram realizados gestos por duas pessoas diferentes. Estes poderiam ou não ser similares, e a tarefa do sujeito era identificar quais pares de gestos eram similares. Era dito ao sujeito: "Nesta prova, duas pessoas vão fazer os gestos. Os gestos são apresentados dois a dois um logo depois do outro. Uma pessoa executa o primeiro gesto e outra pessoa executa o segundo gesto. $\mathrm{O}$ (a) sr.(sra.) deve olhar atentamente os dois gestos e depois o(a) sr.(sra.) deve me dizer se as pessoas fizeram a mesma ação ou não" Em seguida eram apresentados 24 gestos. Destes, quatro eram pares cuja a ação era a mesma e feita de maneira idêntica, oito representavam a mesma ação, mas eram feitos de maneira diferente e 12 eram ações diferentes. 


\subsubsection{Quarta prova: seleção do gesto correto}

A quarta prova também era subdividida em duas partes. Na primeira um objeto aparecia na tela. Em seguida uma pessoa fazia dois gestos, um representava a utilização correta do objeto apresentado, e o outro era um gesto que poderia ser o objeto utilizado de forma inadequada, ou um gesto que não utilizava o objeto apresentado. $\mathrm{O}$ sujeito deveria apontar em qual das duas pantomimas o objeto apresentado era corretamente utilizado. Era dito ao sujeito: "Nesta prova vai aparecer um objeto e em seguida uma pessoa fará dois gestos. Depois de o(a) sr.(sra.) olhar atentamente os dois gestos, você deve me dizer em qual dos dois - no primeiro ou no segundo acontece a ação correta correspondente ao objeto mostrado". Seguia-se a apresentação de 18 objetos seguidos de 18 pares de gestos. Dentre eles, havia seis que continham erros de forma, seis com erros de movimentos e seis nos quais o gesto não tinha nenhuma relação com o objeto apresentado. Na segunda parte da prova eram apresentados pares de gestos convencionais. Antes da apresentação de cada um dos pares era dito pelo examinador qual gesto deveria ser identificado pelo sujeito. Seguia-se a apresentação dos pares de gestos. Dentre os seis apresentados, um gesto era o apontado pelo examinador e o outro era um gesto com mensagem totalmente diferente realizado de maneira igualmente correta. Os gestos que deveriam ser selecionados pelos sujeitos foram os mesmos para todos os indivíduos. Antes do início da segunda parte era dito ao idoso: "Nessa segunda parte, a pessoa vai executar dois gestos que querem dizer alguma 
coisa. Eu vou the dizer um gesto (uma ação) e depois o(a) sr.(sra.) vai olhar atentamente para a pessoa fazendo os dois gestos. Depois dos dois gestos o(a) sr.(sra.) deve me dizer qual dos dois, o primeiro ou o segundo, representa a ação que eu lhe disse".

\subsubsection{Quinta prova: Nomeação}

A quinta prova era de nomeação de gestos. Esta também era dividida em duas partes, uma de gestos que imitavam a utilização de objetos e outra de gestos convencionais. Cada parte consistia de dez gestos. A ordem dada ao sujeito era a mesma: "Agora o(a) sr.(sra.) vai me dizer que gesto o indivíduo estava realizando". Cada uma das partes continha dez gestos.

\subsubsection{Avaliação da confiabilidade}

Para avaliar a confiabilidade intra-examinador de todo o protocolo de reconhecimento de gestos foram selecionados 26 indivíduos da amostra inicial ao acaso. Esses foram reavaliados pelo mesmo examinador com intervalo de duas semanas entre a primeira e a segunda avaliação.

\subsection{Análise Estatística}

Foi inicialmente realizada uma análise descritiva de modo a ressaltar as características básicas gerais e agrupadas por sexo (masculino feminino), por faixa etária (de 60 a 74 anos - igual ou superior a 75 anos) e por faixa de escolaridade (analfabetos, de 1 a 3 anos- de 4 a 7 anos - igual ou superior a 8 anos). Esta análise foi feita tanto no protocolo de produção de gestos (como um todo e separado por comando verbal e imitação) e 
protocolo de reconhecimento de gestos (como um todo e separado em suas cinco provas).

Com o objetivo de podermos comparar 0 desempenho dos entrevistados nas diversas provas, que tinham escalas diferentes, foi feita uma transformação de escala nomeada de grau de desempenho definida abaixo.

$$
\text { Grau de desempenho }=\frac{\text { núm. de pontos obtidos } \times 100}{\text { núm. máximo de pontos da prova }}
$$

As pontuações nas diversas provas ficam na escala de 0 a 100, sendo que 0 significa que não foi obtida pontuação e que quanto maior (mais próximo de 100) o valor do grau de desempenho maior a pontuação obtida na prova. Através destas variáveis pode-se comparar o resultado entre as diversas provas.

O efeito das variáveis independentes ou fatores (sexo, faixa de escolaridade e faixa etária) em cada variável dependente (protocolo de produção de gestos e sua divisão: comando verbal e imitação, protocolo reconhecimento de gestos e sua divisão em cinco provas) foi avaliado pelo modelo de análise de variância (ANOVA) comparando as médias de cada variável dependente nas diversas categorias dos fatores. Posteriormente, para os fatores cuja comparação de média detectou diferença entre suas categorias, comparou-se, através da análise de contraste (teste de Duncan), as médias duas a duas, de modo a estabelecer quais apresentavam diferença entre si. 
Para a comparação da média do grau de desempenho da subdivisão GT e GC das provas 2, 4 e 5 do protocolo de reconhecimento, foi feito o teste de igualdade de médias dados emparelhados e a associação entre estas subdivisões foi quantificada pela correlação de Pearson.

Em todas as comparações foi adotado nível descritivo $p \leq 0,05$.

Como medida da confiabilidade foram utilizados a consistência interna, através do coeficiente $\alpha$ de Cronbach e o teste-reteste avaliado pelo coeficiente de correlação intraclasse. 


\section{RESULTADOS}

Foram avaliados 96 indivíduos divididos nas categorias apresentadas na casuística. A média de idade dos indivíduos avaliados foi de 73,9 anos ( $\mathrm{DP}=7,9)$, sendo que a média da idade das mulheres foi igual a 74,2 anos $(\mathrm{DP}=8,0)$ e dos homens igual a 73,7 anos $(\mathrm{DP}=7,8)$. Os integrantes do grupo A tiveram como média de idade 67,2 anos ( $\mathrm{DP}=4,3$ ) e do grupo $\mathrm{B}, 80,7$ anos $(\mathrm{DP}=3,8)$. A idade dos indivíduos subdividido por escolaridade foi igual a 74,7(DP=7,6), 75,2 (DP=7,4), 72,4 (DP=7,2) e 73,5 (DP=9,3) anos para os analfabetos e os grupos com escolaridade de 1 a 3 anos, 4 a 7 anos e igual ou superior a 8 anos, respectivamente.

A escolaridade média dos 96 indivíduos foi de 4,9 anos ( $D P=5,1)$. Já das mulheres foi igual a 4,8 anos e dos homens, 5. Para os indivíduos do grupo A, a escolaridade média foi igual a 4,7 anos e do grupo B, 5,1. Quanto à média da escolaridade do grupo de 1 a 3 anos, esta foi igual a 2,6 anos, do grupo de 4 a 7 anos foi igual a 4,3 anos e do grupo com escolaridade igual ou superior a 8 anos, a média foi igual a 12,8 anos.

O desempenho dos indivíduos nos testes de rastreio está descrito na tabela 2.

Tabela 2 - Desempenho dos grupos nos testes de rastreio 


\begin{tabular}{lccccc}
\hline TESTE & $\begin{array}{c}\text { Desempenho } \\
\text { geral }\end{array}$ & Analfabetos & $\begin{array}{c}\text { Escolaridade } \\
1 \text { a } 3 \text { anos }\end{array}$ & $\begin{array}{c}\text { Escolaridade } 4 \\
\text { a } 7 \text { anos }\end{array}$ & $\begin{array}{c}\text { Escolaridade igual ou } \\
\text { superior a } 8 \text { anos }\end{array}$ \\
\hline MEEM & 26,5 & 20,8 & 25,2 & 25,9 & 28,4 \\
& $(\mathrm{DP}=2,27)$ & $(\mathrm{DP}=2,17)$ & $(\mathrm{DP}=2,3)$ & $(\mathrm{DP}=1,73)$ & $(\mathrm{DP}=1,31)$ \\
Fluência & 16,8 & 12,9 & 15,7 & 16,1 & 18,6 \\
Verbal & $(\mathrm{DP}=3,56)$ & $(\mathrm{DP}=2,3)$ & $(\mathrm{DP}=3,09)$ & $(\mathrm{DP}=3,69)$ & $(\mathrm{DP}=3,31)$ \\
Memória & 9,1 & 9,1 & 8,8 & 9,1 & 9,4 \\
Figuras & $(\mathrm{DP}=0,92)$ & $(\mathrm{DP}=0,85)$ & $(\mathrm{DP}=1,09)$ & $(\mathrm{DP}=0,83)$ & $(\mathrm{DP}=0,77)$ \\
\hline
\end{tabular}

\subsection{Teste de Produção de gestos}

$\mathrm{Na}$ prova de produção de gestos era possível que o sujeito pontuasse no máximo vinte pontos ao realizar os gestos ao comando verbal. O escore geral da prova de produção ao comando verbal foi de 17,3 (DP=1,8). Já o grau de desempenho (GD) geral foi de $86,6 \%$ $(\mathrm{DP}=8,9)$. Quando o desempenho foi analisado separando-se os indivíduos segundo o sexo obteve-se os seguintes escores: 17,5 $(\mathrm{DP}=1,4 ; \mathrm{GD}=87,7 \%)$ para mulheres e $17,1(\mathrm{DP}=1,7 ; \mathrm{GD}=85,4 \%)$ para homens. Essa diferença não foi estatisticamente significante $(p=0,144)$.

Analisando-se o desempenho dos indivíduos de acordo com a faixa etária o escore foi de $17,7(\mathrm{DP}=1,8)$ para 0 grupo $\mathrm{A}$ e 16,9 $(\mathrm{DP}=1,6)$ para o grupo $\mathrm{B}$. O grau de desempenho foi de $88,6 \%(\mathrm{DP}=9,0)$ para o grupo A e $84,5 \%(D P=8,2)$ para $\circ$ grupo $B$. Esta diferença foi estatisticamente significante $(p=0,001)$.

Em relação à escolaridade, os indivíduos analfabetos obtiveram $16,1(\mathrm{DP}=1,1)$ e grau de desempenho de $80,6 \%$, os que freqüentaram a escola de 1 a 3 anos obtiveram escore igual a $17,1(D P=1,1)$ e grau de 
desempenho 85,4\% (DP=5,7). Já os indivíduos com 4 a 7 anos de escolaridade obtiveram escore igual a 17,6 (DP=1,9) e grau de desempenho $87,9 \%(\mathrm{DP}=9,7)$ enquanto os que freqüentaram a escola por oito anos ou mais obtiveram escore de $18,5(\mathrm{DP}=1,1)$ e grau de desempenho de 92,3\% (DP=5,3). Essa diferença foi estatisticamente significante $(p<0,001)$, sendo que a média da faixa maior ou igual a oito anos foi estatisticamente diferente das outras faixas de escolaridade, 0 mesmo acontecendo com os analfabetos. Por outro lado as outras duas faixas de escolaridade (1 a 3 anos e 4 a 7 anos) foram estatisticamente iguais entre si.

Já na produção de gestos à imitação (escore máximo 34) a média geral foi de 30,5 ( $D P=3,2 ; G D=89,8 \%$ ). Mulheres e homens e grupos $\mathrm{A}$ e $B$, obtiveram escore de 30,9 ( $D P=3,2 ; G D=90,7 \%)$ e $30,2(D P=3,2$; $\mathrm{GD}=88,9 \%)$ e $31,6(\mathrm{DP}=2,7 ; \mathrm{GD}=92,8 \%)$ e 29,5 ( $\mathrm{DP}=3,3 ; \mathrm{GD}=86,8 \%)$, respectivamente. A primeira diferença não foi estatisticamente significante $(p=0,278)$, o mesmo não acontecendo entre os grupos $A$ e $B$, os quais apresentaram diferenças significativas $(p=0,001)$. Indivíduos analfabetos apresentaram escore de $28,5(\mathrm{DP}=3,7 ; \mathrm{GD}=83,7)$, os da segunda faixa de escolaridade apresentaram escore de 30,8 $(\mathrm{DP}=2,5$; $\mathrm{GD}=90,6 \%)$, os da terceira, $30,7(\mathrm{DP}=3,3 ; \mathrm{GD}=90,3 \%)$ e os com maior tempo de freqüência a escola, 32,2 ( $\mathrm{DP}=1,77 \mathrm{GD}=94,7 \%)$. Nesse caso também houve diferença entre os quatro grupos $(p<0,001)$ com os indivíduos analfabetos diferindo das outras três faixas de escolaridade. 
Somando-se o escore das duas provas o escore geral foi de 47,9 ( $\mathrm{DP}=4,5 ; \mathrm{GD}=88,6 \%$ ), com as mulheres obtendo em média 48,4 pontos $(\mathrm{DP}=4,5 ; \mathrm{GD}=89,6 \%)$ e os homens, 47,3 ( $\mathrm{DP}=4,3$ e $\mathrm{GD}=87,6 \%)$, diferença essa não significativa $(p=0,17)$. Já os indivíduos mais jovens obtiveram escore de 49,3 ( $\mathrm{DP}=4,09$ e $\mathrm{GD}=91,3 \%$ ) enquanto os mais velhos pontuaram em média 46,4 ( $\mathrm{DP}=4,5 ; \mathrm{GD}=86 \%)$, diferença essa estatisticamente significante $(p<0,001)$. $O$ grupo de idosos analfabetos obteve 44,6 pontos ( $\mathrm{DP}=5,0 ; \mathrm{GD}=82,6 \%$ ), os com 1 a 3 anos de escolaridade, 47,9 ( $\mathrm{DP}=3,2 ; \mathrm{GD}=88,7 \%$ ), os com 4 a 7 anos, 48,3 $(\mathrm{DP}=4,8 ; \mathrm{GD}=89,4 \%)$ e aqueles com oito ou mais anos de escolaridade, 50,7 ( $\mathrm{DP}=2,6 ; \mathrm{GD}=93,8 \%$ ). Essa diferença também foi significativa, sendo que o grupo de indivíduos analfabetos foi diferente de todos os demais grupos, o mesmo acontecendo com o grupo com oito ou mais anos de escolaridade, enquanto os dois outros grupos tiveram desempenho semelhante. Levando-se em consideração o escore total ponderado na prova não se encontrou diferença significante considerando-se a variável sexo $(p=0,148)$, enquanto idade $(p=0,001)$ e escolaridade $(p<0,001)$ foram fatores que influenciaram o desempenho dos indivíduos na prova, sendo o comportamento da variável escolaridade o mesmo verificado sobre o desempenho geral.

Não foram encontradas interações entre sexo e faixa etária para os escores comando verbal, imitação e escore geral $(p=0,424, p=0,885$ e $p=0,832$; respectivamente). Também não houve interação entre sexo e escolaridade para nenhum dos três escores $(p=0,474$ para 0 comando 
verbal, $p=0,783$ para imitação e $p=0,664$ para 0 escore total). Descartou-se a possibilidade de interação entre idade e escolaridade também para os três escores $(p=0,422, \quad p=0,59$ e $p=0,483$; respectivamente).

Os resultados do desempenho dos indivíduos levando-se em consideração cada um dos gestos das provas de produção estão representados nos gráficos abaixo.

Gráfico 1 - Gráfico do desempenho dos indivíduos em cada um dos itens do teste de produção ao comando verbal.

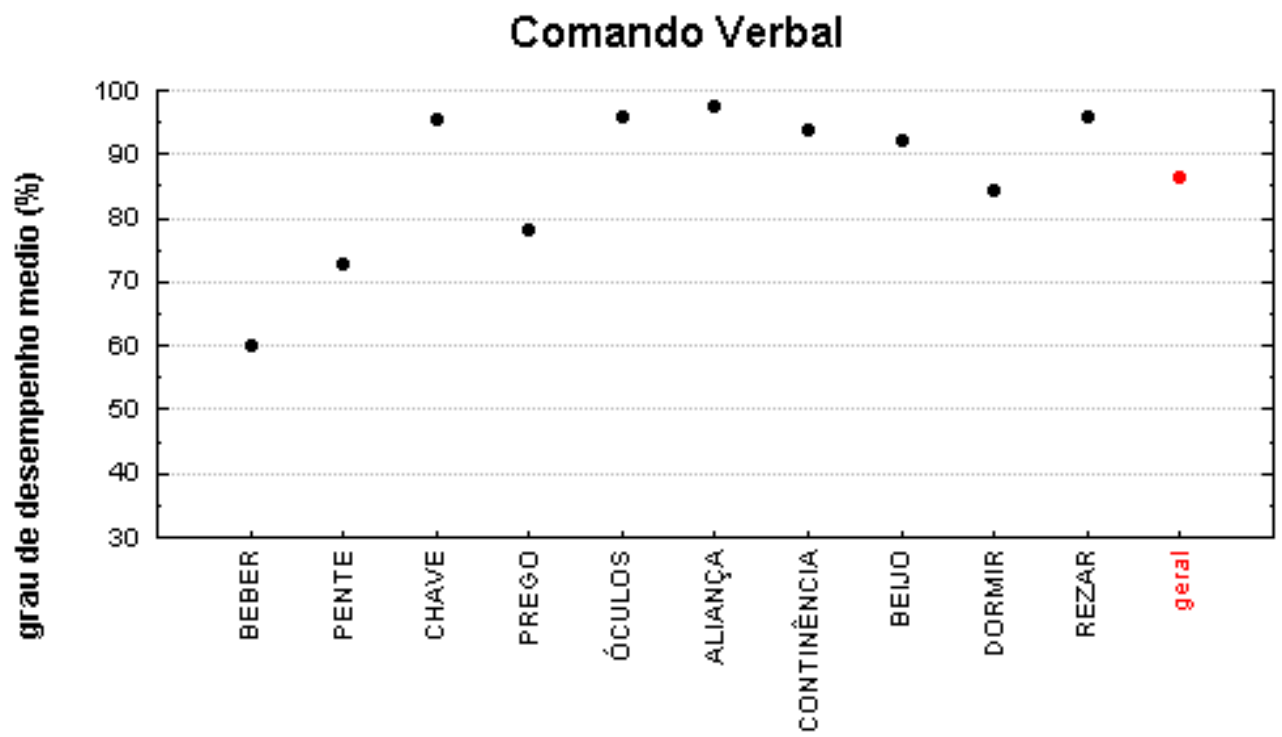

questões 
Gráfico 2 - Gráfico do desempenho dos indivíduos em cada um dos itens do teste de produção à imitação.

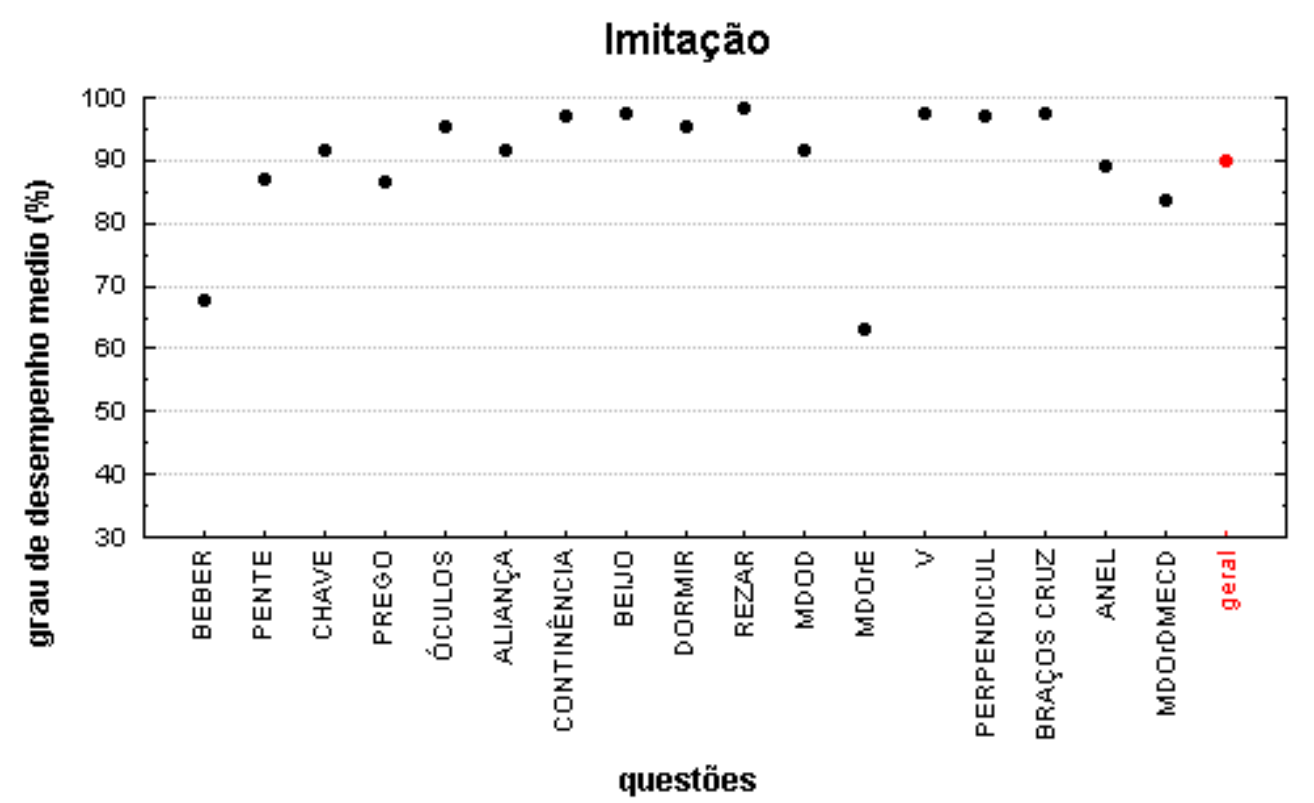

Os gestos beber e usar um pente foram os que obtiveram um menor número de acertos, tanto ao comando verbal quanto à imitação. Isso ocorreu principalmente devido ao enorme índice de erros do tipo parte do corpo como objeto. Os indivíduos que não receberam dois pontos nesses dois itens foram devido ao fato de terem utilizado a mão para representar o objeto, embora à imitação o número de erros tenha caído bastante.

Durante a imitação, outro gesto que não foi realizado de forma correta foi a colocação do dorso da mão direita sobre a orelha esquerda.

\subsubsection{Correlação entre os testes de rastreio e a produção de gestos.}

O coeficiente de correlação entre a produção geral de gestos e o teste do Mini- exame do Estado Mental foi de 0,517, para o teste de fluência verbal foi de 0,367 e para o teste de memória de figuras, 0,166. 


\subsubsection{Confiabilidade inter e intra-examinador.}

O índice de correlação intra-classe para a produção de gestos inter e intra-examinador, bem como o valor do $\alpha$ de Cronbach encontram-se na tabela 3 abaixo.

Tabela 3 - Coeficiente de correlação intra classe e $\alpha$ de Cronbach para o protocolo de produção de gestos

\begin{tabular}{lccc}
\hline & $\begin{array}{c}\text { Correlação intra- } \\
\text { examinador } \\
(\text { IC } 95 \%)\end{array}$ & $\begin{array}{c}\text { Correlação inter- } \\
\text { examinador } \\
(I C ~ 95 \%)\end{array}$ & $\begin{array}{c}\alpha \text { de Cronbach } \\
(\text { IC 95\%) }\end{array}$ \\
\hline Comando verbal & 0,647 & 0,806 & 0,519 \\
Imitação & $0,367 ; 0,82)$ & $(0,574 ; 0,919)$ & $(0,362 ; 0,651)$ \\
Produção de gestos geral & 0,720 & 0,899 & 0,752 \\
Produção de gestos ponderada & $0,467 ; 0,863)$ & $(0,763 ; 0,959)$ & $(0,673 ; 0,818)$ \\
& 0,626 & 0,833 & 0,806 \\
& $(0,322 ; 0,813)$ & $(0,62 ; 0,93)$ & $(0,745 ; 0,858)$ \\
& $(0,231 ; 0,777)$ & $(0,579 ; 0,919)$ & $(0,690 ; 0,861)$ \\
\hline
\end{tabular}

\subsection{Teste de reconhecimento de gestos.}

Levando-se em consideração o teste de reconhecimento de gestos o desempenho médio dos indivíduos foi de 97,9 (DP=10,6) dos 118 possíveis, mostrando um grau de desempenho geral de $83 \%$. 0 desempenho dos indivíduos na prova com um todo está descrito na tabela abaixo. 
Tabela 4 - Desempenho dos grupos na prova de reconhecimento de gestos

\begin{tabular}{|c|c|c|c|c|c|c|c|}
\hline \multicolumn{2}{|c|}{ Sexo } & \multicolumn{2}{|c|}{ Faixa Etária } & \multicolumn{4}{|c|}{ Escolaridade } \\
\hline Feminino & Masculino & 60-74 anos & $\geq 75$ anos & Analfabetos & 1 a 3 anos & 4 a 7 anos & $\geq 8$ anos \\
\hline 102,4 & 100,5 & 103,6 & 99,3 & 87,5 & 95,7 & 96,8 & 103,9 \\
\hline$(\mathrm{DP}=7,36)$ & $(\mathrm{DP}=8,12)$ & $(\mathrm{DP}=6,69)$ & $(\mathrm{DP}=8,2)$ & $(\mathrm{DP}=11,1)$ & $(\mathrm{DP}=7,9)$ & $(\mathrm{DP}=8,2)$ & $(\mathrm{DP}=9,7)$ \\
\hline (GD=84,6\%) & $(\mathrm{GD}=81,4 \%)$ & $(\mathrm{GD}=85,5 \%)$ & $(\mathrm{GD}=80,5 \%)$ & (GD=74,2\%) & $(\mathrm{GD}=84,1 \%)$ & $(G D=84 \%)$ & $(\mathrm{GD}=89,8 \%)$ \\
\hline
\end{tabular}

Foram encontradas diferenças significativas em função do sexo $(p=0,017)$, idade $(p<0,001)$ e dos diferentes níveis de escolaridade $(p<0,001)$. O grupo com escolaridade de 8 anos ou mais e os analfabetos foram diferentes dos outros grupos. Por sua vez, grupos com escolaridade de 1 a 3 anos de 4 a 7 anos, foram iguais entre si. Os mesmos resultados são encontrados quando se levou em consideração o grau de desempenho ponderado.

\subsubsection{Primeira prova}

Dentre os trinta e dois pontos possíveis, o escore geral da primeira prova, levando-se em consideração a amostra como um todo, foi de $25,1(\mathrm{DP}=4,7)$, com grau de desempenho igual a $78,5 \%$. O escore das mulheres foi de 25,5 ( $D P=4,2 ; G D=79,8 \%$ ) e dos homens 24,8 ( $D P=5,2$; $\mathrm{GD}=77,3 \%$ ). Essa diferença não foi estatisticamente significante $(p=0,314)$. Os indivíduos mais novos tiveram escore de 26,2 ( $D P=3,8$; $\mathrm{GD}=82 \%)$ e os mais idosos, 24 ( $\mathrm{DP}=5,3 ; \mathrm{GD}=75,1 \%)$, diferença estatisticamente significante $(p=0,05)$. Entre os indivíduos analfabetos, $o$ escore médio foi de 21,4 ( $\mathrm{DP}=5,3$ e $\mathrm{GD}=66,9 \%$ ), entre aqueles com 
escolaridade de 1 a 3 anos o escore médio foi de 26 ( $D P=3,55 ; G D=$ $81,3 \%$ ), entre os indivíduos com 4 a 7 anos o escore foi de 24,4 ( $D P=4,22$ e $G D=76,2 \%)$ e os com escolaridade maior, de 28,8 ( $D P=2,3$ e $\mathrm{GD}=89,8 \%$ ). Mais uma vez a diferença foi estatisticamente significante $(p<0,001)$, com os grupos de maior e menor escolaridade diferindo dos outros, enquanto os grupos com escolaridade média sendo iguais entre si. Não houve interação entre sexo e faixa etária $(p=0,166)$ e idade e escolaridade $(p=0,716)$, contudo foi encontrada interação significante entre sexo e faixa de escolaridade $(p=0,013)$. $O$ desempenho dos sujeitos em cada um dos trinta e dois gestos da primeira prova deu-se de acordo com o gráfico abaixo. O desempenho dos sujeitos em cada um dos gestos separados por idade, sexo e escolaridade encontra-se no apêndice IV.

Nessa prova os dois gestos que foram reconhecidos por todos os sujeitos foram o gesto de beber água, ao contrário da prova de realização do gesto ao comando verbal, e o gesto de bater continência que por sua vez foi o gesto com maior número de acertos nas provas de produção de gestos.

O desempenho médio de todos indivíduos em cada um dos 32 gestos da primeira prova encontra-se no gráfico abaixo. 
Gráfico 6 - Gráfico do desempenho dos indivíduos em cada um dos itens

da primeira prova do teste de reconhecimento de gestos.

$1^{\text {a Prova }}$

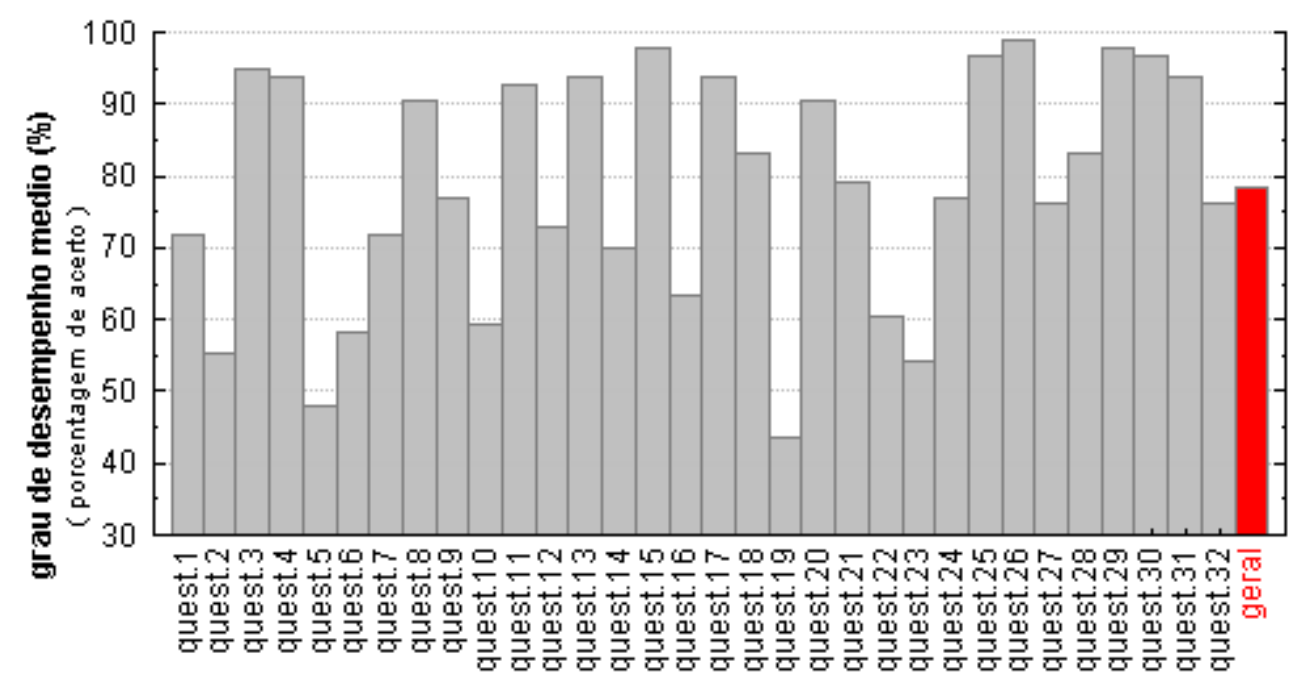

questőes

\subsubsection{Segunda prova}

Tomada a segunda prova como um todo, dos 18 pontos possíveis os indivíduos obtiveram, no geral, um escore médio de 14,7 ( $\mathrm{DP}=2,1$; $\mathrm{GD}=81,8 \%$ ), sendo que o escore das mulheres foi de 14,9 ( $\mathrm{DP}=1,9$; $\mathrm{GD}=82,8 \%)$ e dos homens, $14,6(\mathrm{DP}=2,2 ; \mathrm{GD}=80,9 \%)$. As pontuações de $15(\mathrm{DP}=2,2 ; \mathrm{GD}=83,6 \%)$ e $14,4(\mathrm{DP}=2,1 ; \mathrm{GD}=80,1 \%)$ foram obtidas pelos grupos A e B, respectivamente. Enquanto os indivíduos analfabetos obtiveram 13,5 ( $\mathrm{DP}=2 ; \mathrm{GD}=74,8 \%)$, os de escolaridade de 1 a 3 anos obtiveram média de 14,7 ( $\mathrm{DP}=2,01 ; \mathrm{GD}=81,5 \%)$, os com escolaridade de 4 a 7 anos obtiveram média de 15,2 (DP=2,0; $\mathrm{GD}=84,3 \%$ ) e os com oito anos ou mais, 15,6 ( $\mathrm{DP}=2,0 ; \mathrm{GD}=95,1 \%$ ). Não houve diferença estatisticamente significante entre as variáveis 
sexo $(p=0,417)$ e idade $(p=0,13)$. Já para a variável escolaridade encontrou-se diferença estatisticamente significante $(p=0,002)$. Nesta prova os indivíduos analfabetos diferiram estatisticamente dos outros três grupos, os quais foram iguais entre si.

Não houve interação entre sexo e faixa etária $(p=0,684)$, faixa de escolaridade e sexo $(p=0,737)$ e entre faixa etária e faixa de escolaridade $(p=0,716)$.

\subsubsection{Primeira parte - Gestos transitivos}

A pontuação média dos indivíduos nesta parte foi de 9,5 , sendo que o máximo seria 12. Os sujeitos do sexo masculino e do feminino pontuaram 9,5 (DP $=1,7$ e 1,9, respectivamente; $G D=78,8 \%$ ). Os indivíduos do grupo A atingiram 9,8 ( $\mathrm{DP}=1,8$ e $\mathrm{GD}=81,3 \%$ ) e os do grupo $\mathrm{B}, 9,2$ ( $\mathrm{DP}=1,7 ; \mathrm{GD}=76,4 \%)$. Os indivíduos analfabetos pontuaram 8,7 ( $\mathrm{DP}=13,3 ; \mathrm{GD}=72,6 \%$ ), os com escolaridade de 1 a 3 anos pontuaram 9,5 ( $\mathrm{DP}=1,8 ; \mathrm{GD}=78,8 \%)$ os com escolaridade de 4 a 7 anos apresentaram escore de 9,8 (DP=1,9; $G D=81,2 \%)$ e os com escolaridade de 8 anos ou mais, 9,9 ( $\mathrm{DP}=1,8 ; \mathrm{GD}=82,6 \%)$.

\subsubsection{Segunda parte - Gestos convencionais}

A pontuação média dos indivíduos foi de $5,3(\mathrm{DP}=0,9)$ de seis pontos possíveis. Os escores de 5,4 ( $\mathrm{DP}=0,8 ; \mathrm{GD}=90,6 \%$ ) e 5,1 ( $D P=1,1 ; \quad G D=85,1 \%$ ) foram obtidos por mulheres e homens respectivamente. Tanto o grupo A quanto o grupo B obtiveram um escore de 5,3 ( $D P=0,9$ e 1 respectivamente; $G D=88,2 \%)$. O grupo com 
menor escolaridade pontuou 4,8 ( $D P=1,1 ; G D=79,2 \%)$, o de maior, 5,4 ( $\mathrm{DP}=0,8 ; \mathrm{GD}=95,1 \%$ ). $\mathrm{O}$ grupo com escolaridade de 1 a 3 anos pontuou 5,2 (DP=0,9; $\mathrm{GD}=86,8 \%)$, já o grupo de 4 a 7 anos atingiu 5,4 (DP=0,8; $\mathrm{GD}=90,3 \%)$.

O grau de desempenho médio dos indivíduos na primeira parte da prova foi de $78,8 \%$. Já na segunda parte, que envolvia gestos convencionais, foi de $87,8 \%$. Essa diferença foi estatisticamente significante $(p<0,001)$, porém o índice de correlação de Pearson $(r=-$ 0,076) mostrou que não houve nenhuma relação entre os resultados para cada uma das partes.

A porcentagem de acerto dos indivíduos em cada um dos gestos nas duas partes da segunda prova é mostrada no gráfico abaixo. 0 desempenho dos sujeitos em cada um dos gestos separados por idade, sexo e escolaridade encontra-se no apêndice IV.

Nenhum gesto foi acertado por todos os sujeitos, em nenhuma das duas provas. Na primeira parte apenas três gestos foram acertados por mais de $90 \%$ dos sujeitos, a saber: olhar com um binóculo, escovar os dentes e passar roupa. O gesto de lixar a unha foi reconhecido por menos de $50 \%$ das pessoas e o gesto de segurar um pincel foi reconhecido por aproximadamente $60 \%$ dos sujeitos. Na segunda parte, três dos seis gestos foram acertados por mais de $90 \%$ dos sujeitos: sinalizar que há muito barulho, dizer que a refeição está deliciosa e contar os dedos. 
Gráfico 7 - Gráfico do desempenho dos indivíduos em cada um dos itens

da segunda prova do teste de reconhecimento de gestos.

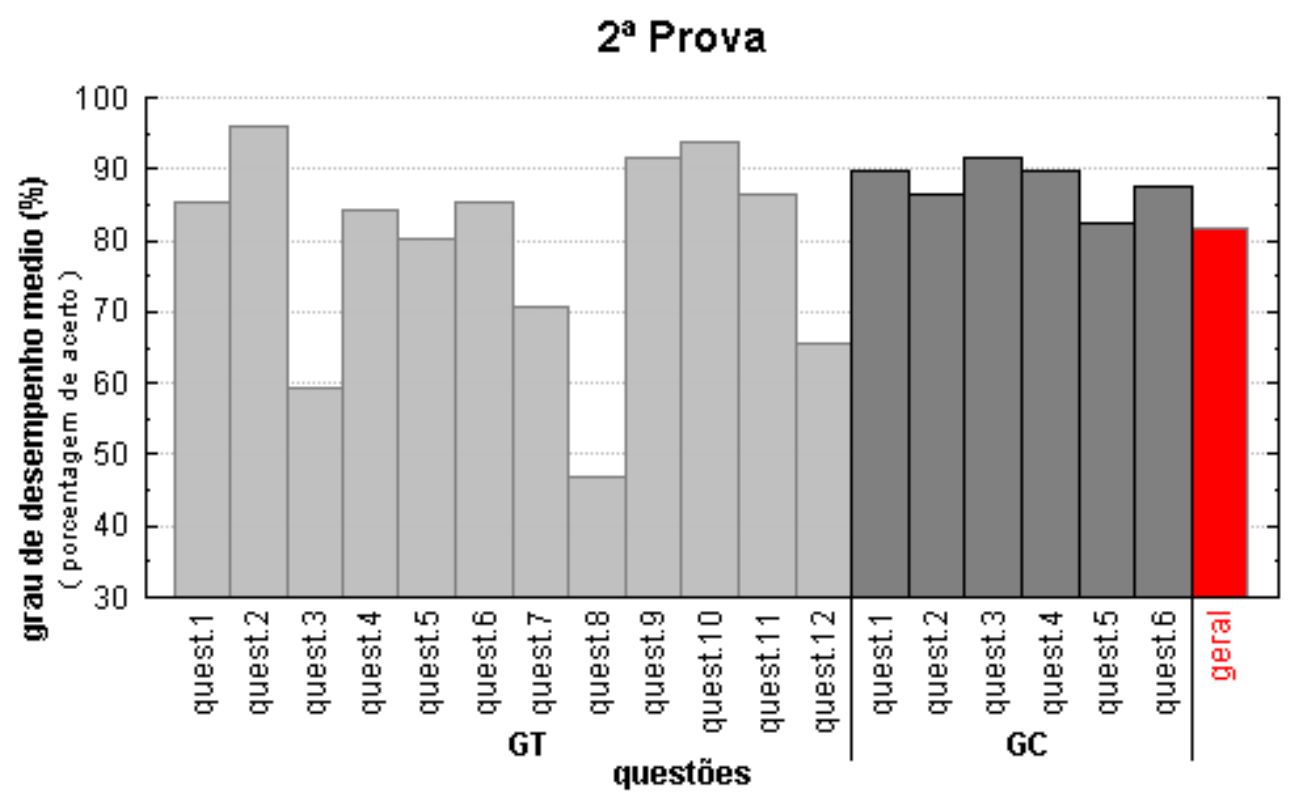

\subsubsection{Terceira prova}

A média de desempenho dos indivíduos foi de $20(\mathrm{DP}=2,5)$ pontos, com pontuação máxima possível de 24 pontos e GD igual a $81,8 \%$. As mulheres pontuaram 20,4 ( $D P=2,2 ; G D=85,1 \%$ ) enquanto os homens obtiveram em média 19,6 ( $\mathrm{DP}=2,6 ; \mathrm{GD}=81,8 \%$ ) pontos, diferença essa não significativa $(p=0,109)$. Já os indivíduos do grupo $A$ obtiveram pontuação média de 20,4 ( $\mathrm{DP}=2,2$ e $\mathrm{GD}=85,2 \%$ ) e os do grupo $\mathrm{B}, 19,6$ ( $\mathrm{DP}=2,6$ e $\mathrm{GD}=81,7 \%)$. De acordo com a faixa de escolaridade os valores obtidos foram 18,8 (DP=2,5; $G D=78,3 \%), \quad 20,3 \quad(D P=2,7$; $\mathrm{GD}=84,7 \%), 20,3(\mathrm{DP}=2,3 ; \mathrm{GD}=84,5 \%)$ e 20,7 ( $\mathrm{DP}=2,1 ; \mathrm{GD}=86,1 \%)$, respectivamente, com o aumento da escolaridade. As diferenças entre os grupos etários não foi significativa $(p=0,091)$. Já em função da escolaridade houve diferença significante $(p=0,038)$, com os indivíduos 
analfabetos diferindo dos outros três grupos, os quais são iguais entre si. Mais uma vez não foram encontradas interações significativas entre as três variáveis $(p=1$ para a interação entre sexo e faixa etária, $p=$ 0,823 , para sexo e faixa de escolaridade e $p=281$, para faixa etária e escolaridade).

As questões com maior porcentagem de acertos ( $90 \%$ ou mais) foram todas aquelas nas quais os gestos eram totalmente diferentes e uma na qual os gestos eram idênticos. Já aquelas nas quais o gesto era o mesmo, embora realizado de formas diferentes, foram acertadas por um menor número de pessoas. A porcentagem de acerto por provas de toda a amostra para cada um dos 24 pares de gestos está demonstrada no gráfico abaixo. O desempenho dos sujeitos em cada um dos gestos separados por idade, sexo e escolaridade encontra-se no apêndice IV. dos

Gráfico 8 - Gráfico do desempenho dos indivíduos em cada um itens da terceira prova do teste de reconhecimento de gestos

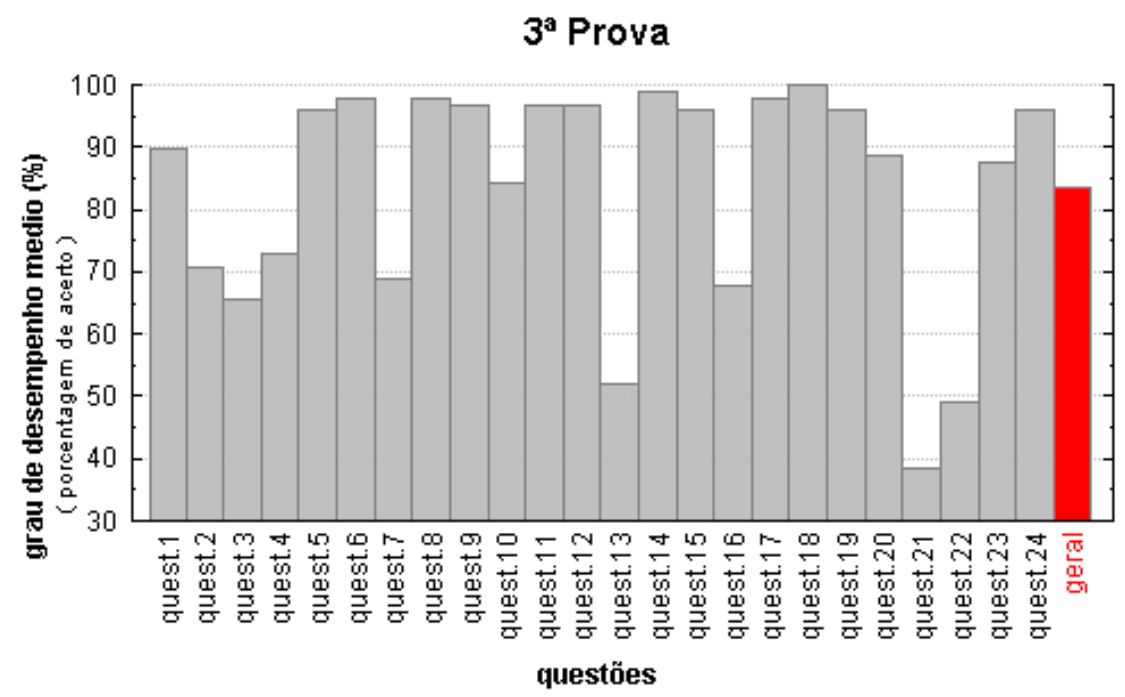




\subsubsection{Quarta prova}

A pontuação média dessa prova de 24 pares de gestos foi de 21 $(\mathrm{DP}=2,2)$, com o maior $\mathrm{GD}$ entre todas as cinco provas, sendo de 87,5\%. As mulheres obtiveram pontuação de 21,4 ( $\mathrm{DP}=2,6 ; \mathrm{GP}=89,1 \%$ ), enquanto os homens atingiram em média 20,6 ( $D P=2,6 ; G D=85,9 \%$ ), mas essa diferença não foi estatisticamente significante $(p=0,103)$. $O$ grupo $A$ alcançou em média 21,4 pontos ( $D P=2,1 ; G D=89,3 \%$ ) enquanto o grupo $B$ pontuou em média 20,5 ( $D P=3,0 ; G D=85,6 \%)$, diferença também sem significado estatístico $(p=0,059)$. Nesta prova o grupo de 4 a 7 anos foi o que apresentou melhor desempenho, com 22 pontos ( $D P=1,8 ; G D=91,8 \%$ ) seguido pelo grupo com 8 ou mais anos de escolaridade com 21,8 pontos ( $\mathrm{DP}=1,5$ e $\mathrm{GD}=91,8 \%$ ), pelo grupo de $1 \mathrm{a}$ 3 anos com 21,2 ( $D P=3 ; G D=88,2 \%$ ) e por fim pelos analfabetos com 19 pontos $(\mathrm{DP}=2,8 ; \mathrm{GD}=79 \%)$. Essas diferenças também foram estatisticamente significantes $(p<0,001)$. Mais uma vez o grupo de indivíduos analfabetos diferiu dos demais grupos, iguais entre si. Não foram encontrados efeitos de interação entre as variáveis pesquisadas: sexo e faixa etária $(p=0,689)$, sexo e escolaridade $(p=0,432)$ e faixa etária e de escolaridade $(p=0,099)$.

\subsubsection{Primeira parte - gestos transitivos}

Nessa prova o grau de desempenho foi de $84,8 \%$ com a pontuação média dos indivíduos ficando em 15,3 ( $\mathrm{DP}=2,3)$. Mulheres apresentaram média de 15,6 ( $D P=2,3 ; G D=86,5 \%)$ e homens de 15 pontos ( $D P=2,3$; 
$\mathrm{GD}=83,1 \%)$. O grupo A pontuou 15,6 ( $\mathrm{DP}=2,1 ; \mathrm{GD}=86,5 \%)$ enquanto $\circ$ grupo B apresentou escore igual a $15(\mathrm{DP}=2,5 ; \mathrm{GD}=83,1 \%)$. Essa parte da prova foi a responsável pelo melhor desempenho dos indivíduos com escolaridade de 4 a 7 anos na soma final. Nessa parte os indivíduos obtiveram escore de 16,2 (DP=1,7; GD=90\%) contra 15,8 ( $\mathrm{DP}=1,5$; $\mathrm{GD}=87,7 \%$ ) do grupo com 8 ou mais anos de escolaridade, 15,3 $(\mathrm{DP}=2,6 ; \mathrm{GD}=85,2 \%)$ para $\circ$ grupo com 1 a 3 anos de escolaridade e $13,7(\mathrm{DP}=2,3 ; \mathrm{GD}=76,2 \%)$ para os analfabetos.

\subsubsection{Segunda prova - Gestos convencionais}

Essa parte da segunda prova foi a que obteve maior índice de acerto entre todas as provas e parte das provas. Dos 6 pontos possíveis a média dos indivíduos foi $5,7(\mathrm{DP}=0,7)$ com grau de desempenho de $95,5 \%$, chegando a $100 \%$ de acertos entre os indivíduos com 8 ou mais anos de escolaridade. Os indivíduos com 1 a 3 anos e 4 a 7 anos de escolaridade apresentaram desempenho médio semelhante, a saber 5,8 pontos, enquanto os analfabetos acertaram em média 5,3 gestos $(\mathrm{DP}=1,1 ; \mathrm{GD}=87,5 \%)$. As mulheres apresentaram 5,8 acertos $(\mathrm{DP}=0,53$; $\mathrm{GD}=96,9 \%)$ e os homens $5,6(\mathrm{DP}=0,9 ; \mathrm{GD}=94,1 \%)$ Indivíduos do grupo A apresentaram em média 5,9 acertos $(\mathrm{DP}=97,9 \%)$ e os do grupo $B, 5,6$ $(\mathrm{DP}=0,9 ; \mathrm{GD}=93,1 \%)$.

Como já foi colocado o grau de desempenho médio dos indivíduos na segunda parte da prova foi de 95,5\%. Já na primeira parte, que envolvia gestos transitivos, foi de $84,8 \%$. Essa diferença foi estatisticamente significante $(p<0,001)$. Também aqui $o$ índice de 
correlação de Pearson $(r=0,351)$ mostrou que não houve nenhuma relação entre os resultados para cada uma das partes.

A porcentagem de acerto dos indivíduos em cada um dos gestos nas duas partes da quarta prova é mostrada no gráfico abaixo. 0 desempenho dos sujeitos em cada um dos gestos separados por idade, sexo e escolaridade encontra-se no apêndice IV.

Figura 9-Gráfico do desempenho dos indivíduos em cada um dos gestos. itens da quarta prova do teste de reconhecimento de

\section{$4^{\mathrm{a}}$ Prova}

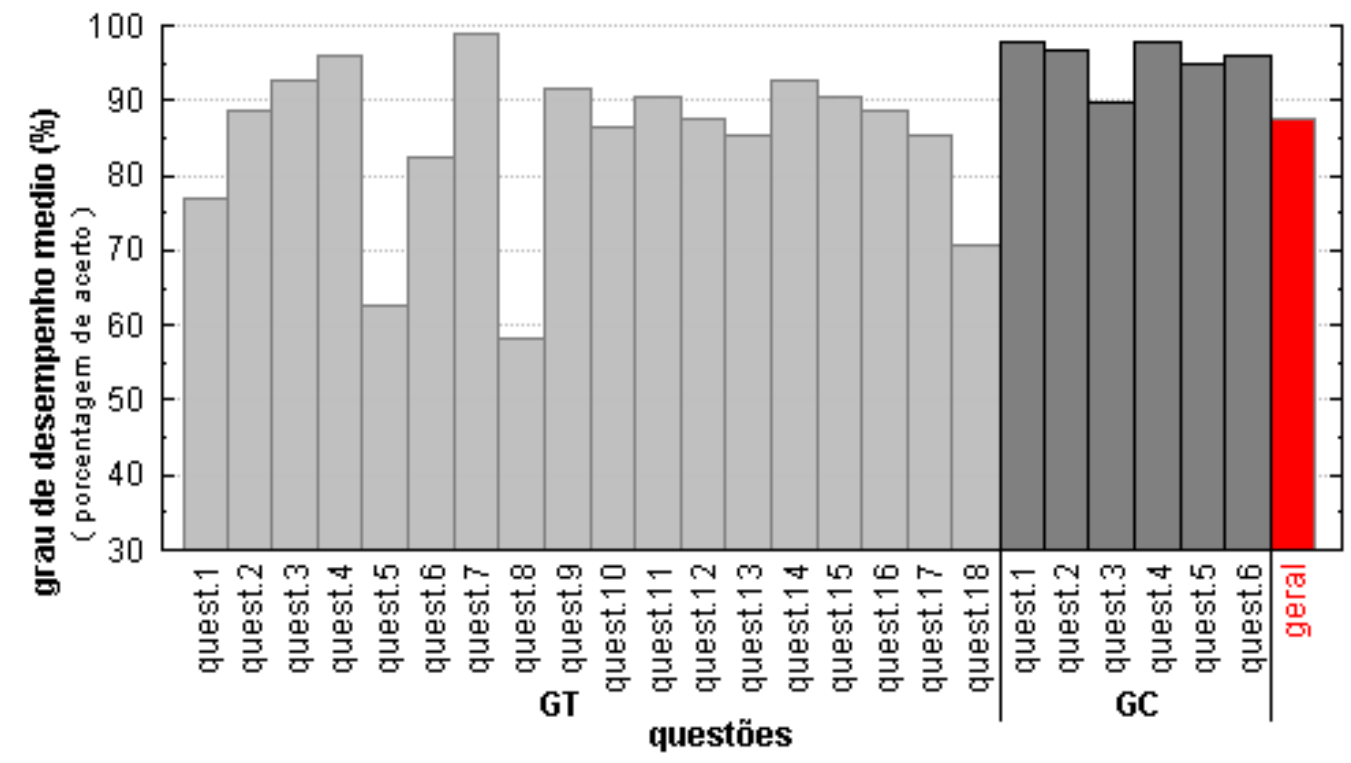

$\mathrm{Na}$ primeira parte dessa prova sete das questões foram respondidas corretamente por mais de $90 \%$ dos indivíduos, dentre elas haviam gestos que envolviam objetos do cotidiano como, por exemplo, ferro de passar roupa, cigarro e telefone. Já outros objetos não são de uso comum no dia-a-dia, como por exemplo, o binóculo. Gestos como 
segurar um pincel e lixar a unha, que não foram identificados em outras provas, obtiveram um número de acertos superior a $90 \%$ nessa prova.

\subsubsection{Quinta prova}

Nessa prova, que consistia na nomeação de 20 gestos, a média de pontos marcados foi de 17,1 ( $\mathrm{DP}=2,7)$. Dentre os indivíduos do sexo feminino a média de pontos foi de 17,6 ( $\mathrm{DP}=2,6 ; \mathrm{GD}=88 \%)$ comparados com 16,5 pontos $(\mathrm{DP}=2,82 ; \mathrm{GD}=82,7 \%)$ dos indivíduos do sexo masculino. Essa diferença foi estatisticamente significante $(p=0,017)$. $O$ escore apresentado pelo grupo mais novo foi de 17,8 ( $D P=1,9$; $\mathrm{GD}=88,8 \%$ ) e pelos mais velhos foi de 16,4 ( $\mathrm{DP}=3,2 ; \mathrm{GD}=82 \%)$. Essa diferença também foi estatisticamente significante $(p=0,003)$. À medida que aumentou o tempo de escolaridade também foi observado um aumento do escore, com o grupo com menor escolaridade apresentando 14,9 pontos ( $\mathrm{DP}=2,9 ; \mathrm{GD}=74,4 \%$ ), o grupo com escolaridade de 1 a 3 anos, 17,1 pontos ( $\mathrm{DP}=2,4 ; \mathrm{GD}=85,4 \%)$, escolaridade de 4 a 7 anos com 17,3 ( $\mathrm{DP}=2,1 \mathrm{GD}=86,3 \%$ ) e 19,1 pontos ( $\mathrm{DP}=1,4$ e $\mathrm{GD}=95,4 \%$ ) para 0 grupo com maior escolaridade. Essa diferença foi estatisticamente significante $(p<0,001)$, com a média do grupo igual ou maior que 8 anos sendo estatisticamente diferente das três outras faixas de escolaridade, bem como os analfabetos, que também se comportaram de maneira diferente dos demais grupos. Os grupos com escolaridade intermediária foram estatisticamente iguais entre si. Não foram encontradas interações entre sexo e idade $(p=0,962)$, sexo e escolaridade $(p=0,736)$ e idade e escolaridade $(p=0,249)$. 
O desempenho dos indivíduos em cada uma das partes dessa prova é apresentado na tabela abaixo.

Tabela 5- Desempenho dos grupos nas duas partes da quinta prova

\begin{tabular}{|c|c|c|c|c|c|c|c|c|c|}
\hline & \multirow[t]{2}{*}{ Geral } & \multicolumn{2}{|c|}{ Sexo } & \multicolumn{2}{|c|}{ Idade } & \multicolumn{4}{|c|}{ Escolaridade } \\
\hline & & Feminino & Masculino & $60-74$ anos & $\geq 75$ anos & Analfabetos & 1 a 3 anos & 4 a 7 anos & $\geq 8$ anos \\
\hline \multirow[t]{3}{*}{ GT } & 8,1 & 8,4 & 7,9 & 8,4 & 7,9 & 6,9 & 8 & 8,3 & 9,3 \\
\hline & $(\mathrm{DP}=1,6)$ & $(\mathrm{DP}=1,5)$ & $(\mathrm{DP}=1,7)$ & $(\mathrm{DP}=1,3)$ & $(\mathrm{DP}=1,9)$ & $(\mathrm{DP}=1,6)$ & $(\mathrm{DP}=1,6)$ & $(\mathrm{DP}=1,3)$ & $(\mathrm{DP}=1,0)$ \\
\hline & $\mathrm{GD}=81,4 \%$ & $\mathrm{GD}=83,8 \%$ & $\mathrm{GD}=79 \%$ & $\mathrm{GD}=84 \%$ & $\mathrm{GD}=81,4 \%$ & $\mathrm{GD}=69,2 \%$ & $\mathrm{GD}=80,4 \%$ & $\mathrm{GD}=82,5 \%$ & $\mathrm{GD}=93,5 \%$ \\
\hline \multirow[t]{3}{*}{$\mathrm{GC}$} & 8,9 & 9,2 & 8,6 & 9,4 & 8,5 & 8 & 9 & 9 & 9,8 \\
\hline & $(\mathrm{DP}=1,3)$ & $(\mathrm{DP}=1,2)$ & $(\mathrm{DP}=1,4)$ & $(\mathrm{DP}=0,8)$ & $(\mathrm{DP}=1,6)$ & $(\mathrm{DP}=1,7)$ & $(\mathrm{DP}=1,0)$ & $(\mathrm{DP}=1,0)$ & $(\mathrm{DP}=0,7)$ \\
\hline & $\mathrm{GD}=89,4 \%$ & $\mathrm{GD}=92,3 \%$ & $\mathrm{GD}=86,5 \%$ & $\mathrm{GD}=93,5 \%$ & $\mathrm{GD}=85,2 \%$ & $\mathrm{GD}=79,6 \%$ & $\mathrm{GD}=90,4 \%$ & $\mathrm{GD}=90 \%$ & $\mathrm{GD}=97,5 \%$ \\
\hline
\end{tabular}

GT $=$ Gestos transitivos; GC = Gestos convencionais

O grau de desempenho médio dos indivíduos na primeira parte da prova foi de $81,4 \%$. Já na segunda parte, que envolvia gestos convencionais, foi de $89,4 \%$. Essa diferença foi estatisticamente significante $(p<0,001)$. Ao contrário das outras duas provas, o índice de correlação de Pearson $(r=0,645)$ mostrou que as duas partes funcionam de maneira semelhante.

A porcentagem de acerto dos indivíduos em cada um dos gestos nas duas partes da quinta prova é mostrada no gráfico abaixo. 0 desempenho dos sujeitos em cada um dos gestos separados por idade, sexo e escolaridade encontra-se no apêndice IV.

Gráfico10 - Gráfico do desempenho dos indivíduos em cada um dos itens da quinta prova do teste de reconhecimento de gestos. 


\section{$5^{\mathrm{a}}$ Prova}

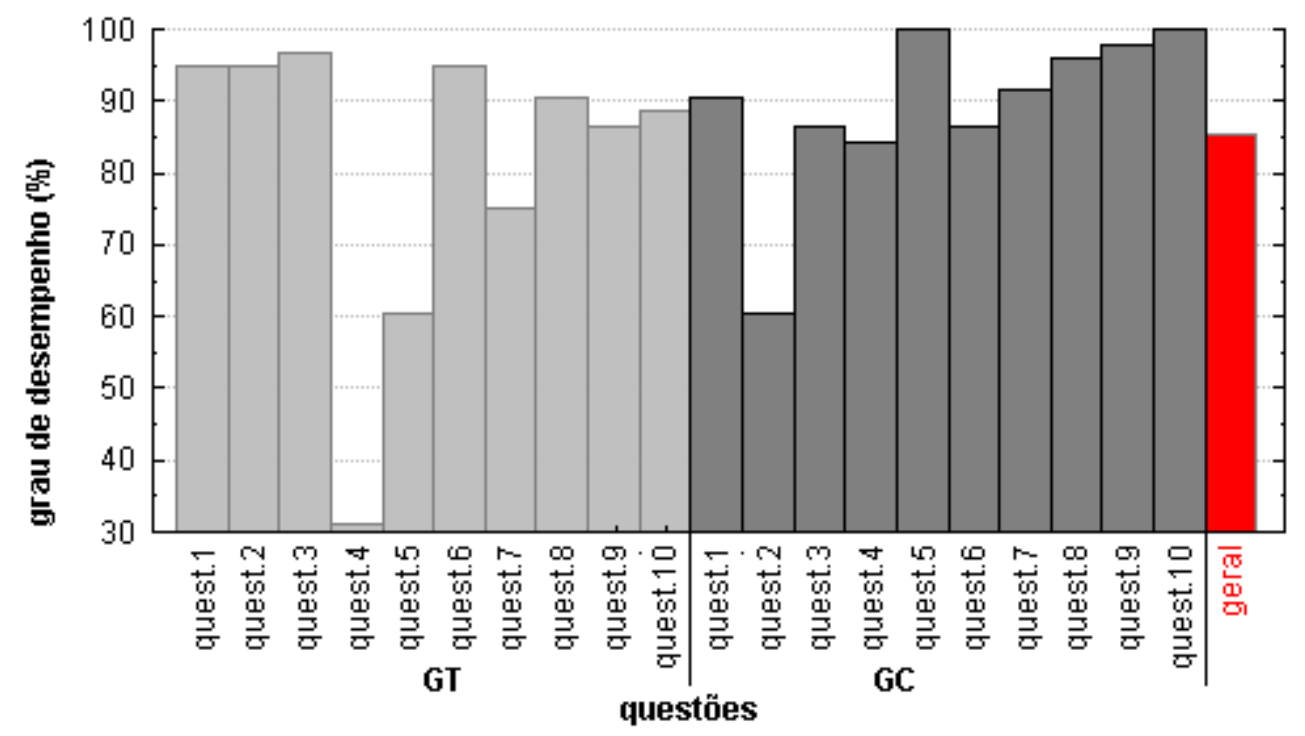

Dos 10 gestos da primeira parte, cinco foram nomeados corretamente por mais de $90 \%$ dos indivíduos. Entretanto um deles, o gesto abrir o jornal (número 4), foi corretamente nomeado apenas por um terço dos indivíduos.

$\mathrm{Na}$ segunda parte, seis dos 10 foram nomeados por mais de $90 \%$, sendo que dois deles, "dar adeus" e "bater palmas", foram acertados por todos os indivíduos.

\subsubsection{Correlação entre testes de rastreio e produção de gestos.}

A correlação entre o reconhecimento geral de gestos e o teste do Mini-exame do Estado Mental foi de 0,643 e quando levou-se em conta o desempenho ponderado, a correlação foi de 0,647 . Com o teste de fluência verbal a correlação foi de 0,474 e com o teste de memória de 
figuras, 0,198. Levando-se em conta o desempenho ponderado a correlação com teste de fluência verbal ficou em 0,49 e com o teste de memória de figuras ficou em 0,203.

\subsubsection{Confiabilidade intra-examinador.}

O índice de correlação intra-classe para a produção de gestos intra examinador, bem como o valor do $\alpha$ de Cronbach encontram-se na tabela 6 abaixo.

Tabela 6- Coeficiente de correlação intra classe e $\alpha$ de Cronbach para o protocolo de produção de gestos.

\begin{tabular}{lcc}
\hline & $\begin{array}{c}\text { Correlação intra- } \\
\text { examinador } \\
(\text { IC } 95 \%)\end{array}$ & $\begin{array}{c}\alpha \text { de Cronbach } \\
(\text { IC 95\%) })\end{array}$ \\
\hline Primeira prova & 0,596 & 0,824 \\
Segunda prova & $(0,279 ; 0,796)$ & $(0,769 ; 0,871$ \\
Terceira prova & 0,500 & 0,506 \\
Quarta prova & $(0,162 ; 0,732)$ & $(0,349 ; 0,639)$ \\
Quinta prova & 0,184 & 0,605 \\
Reconhecimento geral & $(-0,197 ; 0,516)$ & $(0,481 ; 0,711)$ \\
& 0,501 & 0,683 \\
& $(0,148 ; 0,741)$ & $(0,584 ; 0,768)$ \\
& 0,782 & 0,766 \\
& $(0,583 ; 0,893)$ & $(0,692 ; 0,828)$ \\
& 0,736 & 0,882 \\
\hline
\end{tabular}




\section{DISCUSSÃO}

\subsection{Produção de gestos}

De uma maneira geral os indivíduos saíram-se melhor na produção de gestos à imitação quando comparados ao comando verbal, da mesma forma que indivíduos apráxicos descritos na literatura. O desempenho geral dos indivíduos nas provas de produção de gestos ficou acima de $85 \%$, chegando a quase $90 \%$ nas provas de imitação.

O fato de ser mais difícil de realizar pantomimas ao comando verbal pode refletir a complexidade dessa tarefa, a qual é altamente artificial e não acontece no contexto natural.

Nos gestos transitivos observou-se que o menor índice de acerto ocorreu com os gestos "beber" e "usar um pente". Em ambos os casos o grande número de erros ocorreu devido à utilização de parte do corpo como objeto (PCO). Todos os indivíduos que não obtiveram dois pontos nesse item cometeram esse tipo de erro.

A inclusão de erros do tipo PCO como erro de tipo apráxico é ponto de discussão entre os investigadores. Esse tipo de erro é observado na literatura tanto em pacientes como em controles (Dumont et al 2000, Dobigny-Roman et al. 1998, Raymer et al 1997).

Goodglass e Kaplan (1963) foram os pioneiros na descrição desse tipo de erro entre pacientes apráxicos. Para eles a produção de um erro do tipo PCO seria uma tentativa de reduzir o grau de dificuldade de imitar uma tarefa através de uma representação mais concreta do objeto. Raymer et al. 
(1997) colocam que esse tipo de erro ocorre porque existe uma dificuldade na representação correta da postura da mão, a qual é utilizada quando de fato se segura o objeto. Diante dessa dificuldade o sujeito opta por ele mesmo representar o objeto. Contudo os autores colocam que somente quando o sujeito não é capaz de corrigir o erro do tipo PCO esse pode verdadeiramente ser considerado um erro apráxico. Caso contrário, o uso de PCO representa uma resposta culturalmente aceita.

Peigneux et al. (1999) também observaram influência da idade e da escolaridade na ocorrência desse tipo de erro, bem como na correção destes. Para os autores este tipo de erro tem uma representação simbólica e é automaticamente ativado quando se solicita ao sujeito a realização de um gesto transitivo. Tal fato, em vez de representar uma dificuldade em evocar a postura correta da mão usada para segurar o objeto, pode significar uma limitação em inibir a ativação de um gesto mais automático, já que existe maior comprometimento da inibição de respostas automáticas entre idosos.

No presente trabalho não foi solicitado ao sujeito que corrigisse a ocorrência desse tipo de erro, portanto não é possível saber se haveria uma maior ou menor taxa de correção dos erros do tipo PCO em função da escolaridade.

Outros gestos, como "colocar o dorso da mão direita na orelha esquerda", mostraram-se muito difíceis de serem realizados por grande parte dos idosos e, portanto, deve-se estudar a permanência desses gestos no protocolo. 


\subsubsection{As variáveis sexo, idade e escolaridade}

Não foi observada uma influência do sexo nas provas de produção de gestos. Esse era um resultado esperado, já que não existem fatores que possam tornar diferentes os desempenhos de homens e mulheres nesse tipo de tarefa.

Foi observada uma influência da idade no desempenho dos indivíduos, tanto ao comando verbal quanto à imitação. $\mathrm{O}$ declínio cognitivo que vem com a idade pode ser um dos fatores responsáveis pelo pior desempenho de indivíduos idosos.

No tocante à imitação, levando-se em consideração que esse tipo de realização de gesto não necessita de recuperação do gesto da memória, pode-se considerar a dificuldade de imitar gestos como uma dificuldade em se analisar informações vísuo-espaciais entre indivíduos idosos, como já mostrado em outros estudos (Wiederholt et al.,1993; Manly et al., 1999).

A escolaridade foi outra variável a influenciar o desempenho dos indivíduos no protocolo de produção, com indivíduos analfabetos apresentando pior desempenho quando comparados aos outros grupos. $\mathrm{O}$ grupo com maior escolaridade também se diferenciou dos outros grupos, enquanto os dois outros grupos intermediários comportaram-se de maneira uniforme.

A alfabetização pode promover mudanças estruturais no cérebro dos indivíduos (Castro-Caldas et al., 1998). Para Manly et al. (1999) indivíduos alfabetizados apresentam maior facilidade na organização e análise de certos tipos de informação vísuo-espacial, habilidade essa inexistente em indivíduos que não aprenderam a ler e a escrever. 
Um baixo grau de instrução pode ser associado a uma dificuldade maior de se realizar gestos fora do contexto, uma vez que o repertório de gestos pode ser menor e esse fator gerar uma dificuldade maior para evocar a representação correta da postura da mão. Isso gera uma tendência em se criar contextos para o uso de objetos em situação de teste. Nesse caso aconteceriam, por exemplo, os erros do tipo PCO.

\subsubsection{Confiabilidade intra e inter examinador.}

$\mathrm{Na}$ confiabilidade intra-examinador os valores obtidos para o protocolo de produção foram de 0,65 para o comando verbal e 0,72 para a imitação, ficando a correlação do protocolo em 0,626 , indicando que de fato existe uma correlação entre as duas medidas. $\mathrm{Na}$ avaliação inter-examinador essa correlação mostrou-se mais forte ainda, com valores de 0,8 para os gestos ao comando verbal, 0,899 para gestos sob imitação e ficando a correlação do protocolo como um todo em 0,833 .

A consistência interna, medida pelo coeficiente $\alpha$ de Cronbach, foi satisfatória, obtendo-se índice geral de 0,79, aproximando-se muito do valor considerado excelente para trabalhos clínicos (> 0,8; Gifford e Cummings 1999). Em relação à consistência interna das provas de produção ao comando verbal e à imitação em separado, obtiveram-se valores de 0,52 para a primeira e 0,75 para a segunda. De maneira geral, o protocolo tem correlação positiva entre os seus itens e está realmente medindo o desempenho dos indivíduos na produção de gestos. O menor coeficiente apresentado pelos gestos ao comando verbal pode ser devido ao fato de 
haver uma diferença significativa na produção entre os gestos transitivos e convencionais. Outras análises precisam ser feitas para confirmar essa hipótese.

\subsection{Reconhecimento de gestos}

Na literatura há uma escassez de trabalhos normativos da avaliação de reconhecimento de gestos. No levantamento feito foi encontrado apenas um estudo canadense, no qual esse mesmo protocolo foi utilizado.

O desempenho geral dos indivíduos no protocolo ficou em torno de $83 \%$, o que mostra um bom desempenho geral da população avaliada. A primeira prova compreendia 32 gestos, sendo metade dos gestos desprovidos de senso e metade com sentido, onde a tarefa do sujeito era separar os gestos conhecidos dos desconhecidos. Uma análise inicial demonstrou que nenhum dos 96 sujeitos respondeu corretamente a todas as questões, ficando a percentagem de reconhecimento geral em $78,5 \%$. $\mathrm{Na}$ amostra avaliada nesse trabalho, 14 gestos foram reconhecidos por mais de $80 \%$ da população $(43,75 \%$ do total de gestos). Na análise do trabalho canadense, $62 \%$ dos gestos foram reconhecidos por mais de $80 \%$ dos sujeitos. Os gestos convencionais foram os identificados por maior número de indivíduos, seguidos pelos gestos transitivos (exceto o gesto de folhear um jornal) e, por último, os gestos sem sentido. Contudo a amostra do trabalho original era formada por idosos com escolaridade entre 7 e 14 anos.

Se tomarmos como base somente o grupo com escolaridade acima de 8 anos do presente estudo, podemos verificar que 26 gestos ( $81,2 \%$ do total) foram corretamente reconhecidos. 
Na segunda prova quando o sujeito deveria selecionar o gesto correto entre dois, os que apresentavam erro de orientação foram mais facilmente reconhecidos quando comparados com os que apresentavam erros de preensão. $O$ resultado encontrado na população canadense foi o mesmo encontrado em nossa amostra, sugerindo que talvez que erros de preensão sejam uma alteração muito sutil, difícil de ser percebida, uma vez que não alteram a orientação do gesto em relação ao corpo ou mesmo a execução do gesto. Embora o gesto seja realizado de maneira menos eficaz, o objetivo final da ação será alcançado se o sujeito segurar o objeto de outra maneira. Também a maneira de segurar um objeto pode ser diferente de indivíduo para indivíduo, sendo largamente dependente do aprendizado motor de cada um. O fato dos idosos apresentarem na prova de produção de gestos muitos erros onde a forma do objeto não foi respeitada reforça essa proposição.

Nessa prova merece ainda destaque o grande número de pessoas que não foram capazes de reconhecer corretamente 0 ato de segurar um pincel e pintar um muro ou parede. Durante a realização dessa prova muitos indivíduos nomearam o gesto, a despeito do comando dado ser somente escolher o gesto correto. Contudo, a nomeação do gesto gera uma certeza maior de que o indivíduo está compreendendo o gesto realizado e não apenas procurando adivinhar a resposta. $\mathrm{Na}$ segunda parte dessa prova todos os gestos foram reconhecidos por todos os sujeitos, sem haver sinais claros de maior facilidade de reconhecimento de gestos que continham erro na forma da mão ou de orientação. 
A terceira prova, na qual o indivíduo deveria dizer se os gestos eram iguais ou diferentes, a análise estatística mostrou que a variabilidade encontrada não pode ser explicada pelas variáveis consideradas (gênero, idade e escolaridade). Os indivíduos foram capazes de separar de maneira muito eficiente os gestos que eram idênticos dos que eram diferentes, sendo ineficientes no reconhecimento de pares de gestos com mesmo significado realizados de maneira diferente. $\mathrm{O}$ comportamento apresentado pelos sujeitos dessa amostra também está de acordo com o os dados canadenses. Isso sugere que ou o comando da prova deva ser alterado, ou então a prova deva ser editada e os gestos semelhantes, mas não idênticos, retirados.

A quarta prova foi a que obteve maior índice de acerto, o que também ocorreu no estudo canadense. Não houve maior facilidade em escolher o gesto correto dependendo do tipo de erro apresentado. Note-se que nesta prova um dos gestos com maior índice de reconhecimento foi o gesto de pintar um muro. Esse fato, somado à maior taxa de acerto, indica que o fornecimento de uma pista (como o objeto ou o próprio gesto) torna mais fácil a recuperação da memória da forma correta de realização do gesto.

A quinta e última prova, de nomeação dos gestos, mostrou que alguns gestos são identificados por pouquíssimas pessoas, como por exemplo, folhear um jornal, o que é especialmente verdade para os sujeitos analfabetos. Outra constatação é que da mesma forma que indivíduos canadenses responderam "colocar um fone de ouvido" para "colocar uma touca" e "datilografar" ou "digitar" para "tocar piano". Ressalta-se também o 
fato de um grande número de onomatopéias terem sido utilizadas para descrever os gestos da segunda parte da prova, especialmente por aqueles indivíduos com menor escolaridade.

De um modo geral os dados aqui apresentados estão de acordo com os encontrados na população canadense, o que indica que o protocolo, ou o reconhecimento de gestos, não sofre grande influência cultural.

\subsubsection{As variáveis sexo, idade, e escolaridade}

As três variáveis analisadas, sexo, idade e escolaridade, influenciaram no desempenho dos indivíduos nas provas de reconhecimento.

Apesar da variável gênero não influenciar as quatro primeiras provas, sua influência na quinta prova deu-se de maneira expressiva de forma a influenciar o resultado geral da prova. Essa prova consistia na nomeação de gestos observados pelo sujeito. Uma hipótese seria que os gestos apresentados fariam parte mais do cotidiano feminino do que do masculino. Todavia essa não parece uma explicação satisfatória, uma vez que os gestos como "destrancar uma porta", "beber um copo de água", "dar uma bronca" e "dar adeus" fazem parte do cotidiano tanto de pessoas do sexo feminino quanto do sexo masculino.

Wiederlholt et al. (1993) compararam o desempenho de mulheres e homens em vários testes neuropsicológicos e mostraram que as mulheres saíram-se melhor em tarefas verbais, enquanto os homens apresentaram

melhor desempenho em tarefas vísuo-espaciais e vísuo-construtivas. A quinta prova é a única prova do teste de reconhecimento que exigia uma maior expressão verbal, uma vez que nessa prova o sujeito deveria nomear 
o gesto, enquanto nas outras a resposta consistia na escolha entre duas alternativas pré-determinadas (por exemplo, primeiro ou segundo, conheço ou não conheço).

Os sujeitos mais idosos apresentaram pior desempenho em todas as provas do protocolo de reconhecimento. Na literatura é bem estabelecido que o aumento da idade e a presença de declínio cognitivo são inversamente proporcionais à capacidade de desempenho neste tipo de tarefa. Peigneux e van der Linden (1999) mostraram a ocorrência de maior número de erros do tipo PCO entre indivíduos idosos quando comparados a adultos jovens. Dolman et al. (2000) mostraram que a idade é capaz de influenciar alguns componentes da memória de trabalho, entre eles o span de gestos. Wiederholt et al. (1993) também observaram que o desempenho em diversos testes neuropsicológicos decresceu progressivamente à medida em que a idade aumentava. O reconhecimento de gestos parece, portanto, ser mais um domínio cognitivo a sofrer influência da idade.

A escolaridade também influenciou no resultado final do reconhecimento gestual. Tomado o protocolo de reconhecimento como um todo é possível se distinguir três grupos principais: os analfabetos, os quais obtiveram escores menores em todas as provas, os grupos com escolaridade intermediária (ou seja de 1 a 3 anos e de 4 a 7 anos) que se comportaram de forma homogênea e um terceiro grupo formado por aqueles sujeitos com escolaridade igual ou superior a oito anos.

Analisando-se as provas de maneira separada verifica-se que na segunda, terceira e quarta provas existiram na verdade dois grandes grupos: 
os analfabetos e todos os demais grupos de escolaridade. Na primeira prova o sujeito deveria discriminar os gestos que apresentavam algum significado daqueles que não apresentavam significado nenhum. Já na última prova o sujeito deveria nomear os gestos apresentados.

A falha na primeira prova ocorreu principalmente devido ao fato dos indivíduos atribuírem significados a gestos sem significado, mais do que não reconhecerem gestos convencionais e transitivos. Isso pode ser observado pelo fato dos gestos sem significado obterem as menores taxas de reconhecimento, ou seja, em vez do sujeito responder que não reconhecia o gesto ele respondia que reconhecia, atribuindo a ele, na maioria das vezes, um significado. Esse resultado demonstra uma tendência desses indivíduos a atribuir significados a estímulos por eles desconhecidos.

Castro-Caldas et al. (1998) e Reis e Castro-Caldas (1997) ao examinarem a capacidade de mulheres idosas analfabetas e alfabetizadas de repetir palavras e não palavras, relatam que as analfabetas foram capazes de repetir palavras da mesma forma que as alfabetizadas, porém cometeram mais erros e apresentaram uma tendência em transformar não palavras em palavras. Estes resultados indicam que no tocante à linguagem existem dificuldades em lidar com não palavras, da mesma forma que os sujeitos desse estudo apresentaram dificuldades em lidar com "não gestos". Sujeitos analfabetos parecem apresentar dificuldades no processamento de informações novas, ou seja, talvez haja uma limitação ou um atraso no processo de procurar entre todo o léxico de ação o gesto sem sentido 
apresentado e como a tarefa não é bem sucedida o processo mais fácil seria atribuir um significado a esse gesto.

Indivíduos analfabetos também apresentam dificuldade para nomear objetos apresentados sob forma de desenho ou fotografia, mas não o próprio objeto (Reis et al., 2001). Segundo estes autores, a performance em tarefas de nomeação visual é principalmente dependente dos sistemas de reconhecimento visual e processamento de linguagem, bem como da interação ou interface entre esses sistemas. Em paralelo com a aquisição de conhecimento ortográfico na escola, os sujeitos alfabetizados praticam a tarefa de interpretar representações esquemáticas em duas dimensões, o que torna os sujeitos alfabetizados mais familiarizados em decodificar e interpretar informações em duas dimensões.

A nomeação de objetos por confrontação visual depende da adequada percepção da forma, do acesso a um conhecimento semântico e visual prévios para o reconhecimento, de acesso ao léxico mental, e finalmente da organização articulatória da resposta verbal. Portanto, a educação formal e o aprendizado da leitura e escrita, modulam o sistema cognitivo, envolvido na nomeação de representações em duas dimensões de objetos reais.

Essa alteração no processamento das imagens em duas dimensões pode ser a responsável pelo pior desempenho dos indivíduos analfabetos nessas tarefas de reconhecimento. Essa dificuldade também pode ser reforçada pelo resultado da quinta prova, na qual a tarefa dos indivíduos era apenas nomear o gesto. Caso a tarefa de reconhecimento tivesse sido realizada em três dimensões esse déficit poderia ser minimizado. Todavia 
seria muito difícil realizar um protocolo de reconhecimento de gestos em três dimensões uma vez que seria praticamente impossível o examinador realizar os gestos de maneira semelhante para todos os sujeitos.

As diferenças sócio-culturais podem ser outra explicação para um pior desempenho dos indivíduos analfabetos e o fato dos indivíduos analfabetos serem praticamente incapazes de reconhecer o gesto de folhear o jornal fala a favor dessa explicação. Contudo, na amostra estudada havia sujeitos analfabetos comerciantes, outros engajados em programas culturais para a terceira idade, da mesma forma que nos outros grupos também foram encontrados sujeitos com o mesmo perfil. Um melhor controle das características sociais e culturais da amostra poderia eventualmente diminuir essas diferenças.

Por outro lado, indivíduos com escolaridade mais elevada de uma forma geral apresentam desempenho superior que os demais. Na literatura existem dados que mostram que indivíduos que freqüentaram a faculdade, sem obrigatoriamente ter completado o curso, apresentam desempenho superior em vários testes neuropsicológicos quando comparados a indivíduos que freqüentaram apenas o colegial, sujeitos esses com o mesmo nível sócio-cultural (Wiederholt et al., 1993). Como mencionado acima, pequenas variações na escolaridade também levam a um pior ou melhor desempenho na produção de gestos. Portanto, existe possivelmente um benefício cognitivo de um maior tempo de educação formal, quando outras habilidades são desenvolvidas, não apenas a linguagem escrita. 
Castro-Caldas et al. (1999) avaliaram a estrutura do corpo caloso de sujeitos alfabetizados e não alfabetizados e encontraram diferenças entre os dois grupos. Os autores propuseram que o aprendizado formal da leitura e da escrita no momento adequado tem implicações biológicas e funcionais no desenvolvimento do sistema cognitivo e que o crescimento progressivo do corpo caloso é um reflexo da aquisição de informação.

\subsubsection{Gestos transitivos $x$ gestos convencionais}

De um modo geral os gestos convencionais são mais facilmente reconhecidos pelos idosos quando comparados aos gestos transitivos. Isso pode ser observado na segunda, quarta e quinta provas, quando foi possível comparar o desempenho nas duas partes da prova, mas também na primeira prova, na qual a maioria dos gestos reconhecidos por mais de $80 \%$ da população deu-se entre aqueles gestos convencionais.

Da mesma maneira que imitar o uso de objetos, reconhecer uma pantomima de uso de objetos é uma tarefa bem mais artificial do que reconhecer um gesto convencional. No dia a dia das pessoas muitos gestos convencionais são utilizados para transmitir uma mensagem sem que se precise fazer uso de palavras (por exemplo, dar adeus), para reforçar um discurso (como, por exemplo, quando se chama a atenção de uma criança) ou até mesmo quando não se pode ou não se deve utilizar a linguagem falada (por exemplo, pedir silêncio). Essa parece ser a explicação mais lógica.

Mozaz et al. (2002) mostraram que os sujeitos que avaliaram, também idosos normais, apresentaram um maior número de erros ao reconhecer 
gestos transitivos em comparação a gestos convencionais. Os autores sugerem que as representações destes últimos sejam ativadas de forma diferente do que as representações relacionadas aos gestos transitivos. Essa diferença na ativação deve ocorrer justamente porque os gestos convencionais são comumente utilizados durante a comunicação não verbal.

Infelizmente não foi feita comparação entre a produção de gestos com e sem sentido para saber se essa maior facilidade em reconhecer gestos convencionais se aplica também à produção. Porém essa análise poderá ser feita numa próxima fase do trabalho.

\subsubsection{Confiabilidade}

A confiabilidade intra-examinador também apresentou valores satisfatórios para o protocolo de reconhecimento de gestos. O protocolo como um todo obteve um valor de 0,77 , mais uma vez indicando uma correlação forte entre as duas avaliações. Analisando-se individualmente, os valores variaram de 0,182 para a terceira prova até 0,782 para a quinta prova.

A consistência interna medida pelo coeficiente $\alpha$ de Cronbach foi satisfatória obtendo-se índice geral de 0,88, mais uma vez excedendo o valor considerado excelente para estudos clíncios (Gifford e Cummings, 1999).

Levando-se em consideração a baixa correlação e a variabilidade apresentada pela terceira prova (a qual não pode ser explicada pelas variáveis sócio-demográficas) sugere-se a retirada dessa prova do protocolo.

Os resultados obtidos nesse trabalho levantam ainda uma série de hipóteses e muitas outras análises podem ainda ser feitas. Contudo 
restringimos a análise àquela necessária para atingirmos os objetivos propostos para esse trabalho. Temos a certeza que muitos outros estudos poderão ser desenvolvidos a partir deste, inclusive a continuação do processo de validação e de determinação da confiabilidade dos protocolos. Esta será sem dúvida uma das maiores contribuições, dada a escassez de protocolos de avaliação de praxias que possam ser utilizados tanto na prática clínica quanto em pesquisa. 


\section{CONCLUSÕES}

-De forma global os indivíduos saíram-se muito bem em ambos os protocolos, com desempenho médio acima de $85 \%$ no protocolo de produção e acima de $83 \%$ no de reconhecimento.

-A idade e a escolaridade foram as variáveis que influenciaram tanto o escore de produção quanto o de reconhecimento. $O$ sexo influenciou apenas o protocolo de reconhecimento.

- De um modo geral puderam-se identificar três grupos em relação ao desempenho de acordo com a escolaridade: os analfabetos, os com escolaridade de 1 a 7 anos e aqueles com escolaridade igual ou superior a oito anos.

-O analfabetismo influenciou de maneira significativa 0 desempenho dos indivíduos em provas de avaliação de praxias, assim como o faz em outros testes neuropsicológicos.

\subsection{Protocolo de produção de gestos}

- Os indivíduos obtiveram um desempenho ligeiramente superior na prova de imitação quando comparada ao comando verbal, da mesma maneira que os indivíduos apráxicos descritos na literatura.

- Nas provas de produção de gestos como um todo as variáveis idade e escolaridade influenciaram de forma significante 0 desempenho dos sujeitos.

- Os gestos que apresentaram um grande número de erros devem ser substituídos ou eliminados do protocolo. 
-O protocolo de produção de gestos apresentou elevada confiabilidade tanto intra quanto inter-examinador e a consistência interna foi considerada excelente.

\subsection{Protocolo de reconhecimento de gestos}

- Nas prova de reconhecimento de gestos todas as variáveis analisadas (idade, sexo e escolaridade) influenciaram o desempenho dos indivíduos.

- Com relação ao desempenho em função do nível educacional, três grupos apresentaram comportamento distinto: analfabetos, indivíduos com escolaridade de 1 a 7 anos e aqueles com 8 anos ou mais.

- Tomadas as provas como um todo não houve efeito de interação entre sexo e faixa etária, sexo e faixa de escolaridade e faixa etária e faixa de escolaridade, mostrando que realmente idade, sexo e escolaridade influenciam de forma independente 0 desempenho nas tarefas de reconhecimento.

- Os gestos convencionais foram mais facilmente reconhecidos do que os gestos transitivos.

-O protocolo de reconhecimento de gestos apresentou elevada confiabilidade tanto intra quanto inter-examinador e a consistência interna foi considerada excelente. 


\section{REFERÊNCIAS BIBLIOGRÁFICAS}

Barbieri C, De Renzi E. The executive and ideational components of apraxia. Cortex. 1988; 24:535-43.

Benke T. Two forms of apraxia in Alzheimer's disease. Córtex. 1993; $.29: 715-25$.

Blondel A, Desgranges B, de la Sayette V, Schaeffer S, Benali K, Lechavalier B, Viader F, Eustache F. Disorders in intentional gestural organization in Alzheimer's disease: combined or selective impairment of the conceptual and production systems? Eur J Neurol. 2001; 8:629-41.

Brucki SMD. Dados normativos para o uso do teste de fluência verbal (categoria animal) em nosso meio [Tese]. São Paulo: Universidade Federal de São Paulo. Escola Paulista de Medicina; 1996.

Butler, JA. How comparable are tests of apraxia? Clin Rehabil. 2002; 16:38998.

Caramelli P, Croisile B, Fontaine FS. Protocole d'Évaluation de la Production des Gestes, Montreal: Centre de recherche du Centre hospitalier Côte-des Neiges; 1994. 
Carrilho PEM. Apraxias ideomotora e ideatória. In: Nitrini R, Caramelli P, Mansur LL, editores. Neuropsicologia - das bases anatômicas a reabilitação. São Paulo:Clinica Neurológica do HCFMUSP; 1996. p.259-74.

Castro-Caldas A, Petersson KM, Reis A, Stone-Elander S, Ingvar M. The illiterate brain: learning to read and write during childhood influences the functional organization of the adult brain. Brain 1998; 121:1053-63.

Castro-Caldas A, Cavaleiro Miranda P, Carmo I, Reis A, Leote F, Ribeiro C, Ducla-Soares E. Influence of learning to read and write on the morphology of the corpus callosum. Eur J Neurol. 1999; 23-8.

Della Sala S, Lucchelli F, Spinnler H. Ideomotor apraxia in patients with dementia of Alzheimer type. J Neurol. 1987; 234:91-3.

De Renzi E, Motti F, Nichelli P. Imitating gestures: a quantitative approach to ideomotor apraxia. Arch Neurol. 1980; 37:6-10.

De Renzi E, Faglioni P, Sorgato P. Modality specific and supramodal mechanisms of apraxia. Brain. 1982; 105:301-12.

De Renzi E, Lucchelli F. Ideational apraxia. Brain. 1988; 111:1173-85. 
Derouesné C, Lagha-Pierucci S, Thibault S, Baudouin-Madec V, Lacomblez L. Apraxic disturbances in patients with mild to moderate Alzheimes's disease. Neuropsychologia. 2000; 38:1760-69.

Dobigny-Roman N, Dieudonne-Moinet B, Tortrat D, Verny M, Forette B. Ideomotor apraxia test: a new test of imitation of gestures for elderly people. Eur J Neurol. 1998; 5:571-8.

Donkervoot M, Dekker J, Van Dende E, Stehmann-Saris JC, Deelman BG. Prevalence of apraxia among patients with a first left hemisphere stroke in rehabilitations centers and nursing homes. Clin Rehabil. 2000; 14:130-6.

Dolman R, Roy EA, Dimeck PT, Hall CR. Age, gesture span and dissociations among component subsystems of working memory. Brain Cogn.2000; 43:164-8.

Dumont C, Ska B. Pantomime recognition impairment in Alzheimer's Disease. Brain Cogn. 2000; 43 (1-3): 177-81.

Dumont C, Ska B, Joanette Y. Conceptual apraxia and semantic memory deficit in Alzheimer's disease: two sides of the same coin? $J$ Int Neuropsychol Soc. 2000; 6:693-03. 
Folstein MF, Folstein SE, McHugh PR. "Minimental state": A practical method for grading the cognitive state of patients for the clinician. $J$ Psychiatr Res. $1975 ; 12: 189-98$.

Gifford DR, Cummings JL. Evaluating dementia screening testes. Methodologic standards to rate their performance. Neurology.1999; 52: 2247.

Geschwind N. Disconnexion syndromes in animals and man. Brain. 1965; 88:585-644.

Goldenberg G. Imitating gestures and manipulating a manikin - the representation of the human body in ideomotora apraxia. Neuropsychologia. 1995; 33:63-72.

Goldenberg G. Defective imitation of gestures in patients with demage in the left or right hemispheres. J Neurol Neurosurg Psychiatry. 1996; 61:176-80.

Goldenberg G, Hagmann S. The meaning of meaningless gestures: a study of visuo-imitative apraxia. Neuropsychologia. 1997; 35:333-41.

Goldenberg G, Hagmann S. Tool use and mechanical problem solving in apraxia. Neuropsychologia. 1998; 36:581-91. 
Goldenberg G, Laimgruber K, Hermsdörfer J. Imitation of gestures by disconnected hemispheres. Neuropsychologia. 2001; 39: 1432-43.

Goldenberg G, Strauss S. Hemisphere asymmetries for imitation of novel gestures. Neurology. 2002; 59:893-97.

Goodglass H, Kaplan E. Disturbance of gestures and pantomime in aphasia. Brain.1963; 86:703-20.

Graff-Radford NR, Welsh K, Godersky J. Callosal apraxia. Neurology. 1987; $37: 100-5$.

Halsband U, Schmitt J, Weyers M, Binkofski F, Grützner G, Freund HJ. Recognition and imitation of pantomimed motor acts after unilateral parietal and premotor lesions: a perspective on apraxia. Neuropsychologia. 2001; 39:200-16.

Heath M, Roy EA, Westwood D, Black SE. Patterns of apraxia associatede with the production of intransitive limb gestures following left and right hemisphere stroke. Brain Cogn. 2001; 46 (1-2): 165-69.

Heilman KM; Rothi LJ; Valenstein E. Two forms of ideomotor apraxia Neurology. 1982; 32:342-6. 
Heilman KM.; Rothi LJ. Apraxia. In: Heilman KM.; Valenstein E, editors. Clinical neuropshychology. 2a ed. New York: Oxford University Press; 1985. p.131-150.

Heilman KM, Maher LM, Greewald ML, Rothi LJG. Conceptual apraxia from lateralized lesions. Neurology. 1997; 49:457-64.

Kandel ER, Schwartz JH, Jessel TM. Principles of neural science.4a ed. New York; 2000.

Kokmen E, Ozekmikci S, Cha $\mathrm{RH}$, O’Brien PJ. Testing for apraxia in neurological patients: a descriptive study in two diverse cultures. Eur $J$ Neurol. 1998; 5:175-80.

Lausberg H, Cruz RF, Kita S, Zaidel E, Ptito A. Pantomime to visual presentation of objects: left hand dyspraxia in patients with complete callosotomy. Brain. 2003; 126:343-60.

Leiguarda RC, Promstaller PP, Merello M, Starkstein S, Lees AJ, Marsden CD. Apraxia in Parkinson's disease, progressive supranuclear palsy, multiple system atrophy an neuroleptic-induced parkinsonism. Brain. 1997; 120:7590. 
Leiguarda RC, Marsden CD. Limb apraxias: higher-order disorders of sensorimotor integration. Brain. 2000;123:860-79.

Manly JJ, Jacobs DM, Sano M, Bell K, Merchant CA, Small SA, Stern Y. Effect of literacy on neuropsychological test performance in nondemented, education-mathched elders. J Int Neuropsychol Soc. 1999; 5:191-202.

Mozaz MJ. Ideational and ideomotor apraxia: a qualitative analysis. Behav Neurol. 1992; 5:11-7.

Mozaz M, Rothi LJG, Anderson JM, Crucian GP, Heilman KM. Postural knowledge of transitive pantomimes and intransitive gestures. $J$ Int Neuropsychol Soc. 2002; 8:958-62.

Nitrini R, Lefèvre BH, Mathias SC, Caramelli P, Carrilho PEM, Sauaia N, Massad E, Takiguti C, Silva IO, Porto, CS, Magila MC, Scaff M. Neuropsychological tests of simple application for dementia diagnosis. Arq. Neuropsiquiatr. 1994; 52:457-65.

Ochipa C, Rothi LJG, Heilman KM. Ideational apraxia: a deficit in tool selection and use. Ann Neurol. 1989; 25:190-3.

Ochipa C, Rothi LJG, Heilman KM. Conceptual apraxia in Alzheimer's Disease. Brain. 1992; 115:1061-71. 
Pedersen PM, Jorgensen HS, Kammersgaard LP, Nakayama H, Raaschou HO, Olsen TS. Manual and oral apraxia in acute stroke, frequency and influence on functional outcome: the Copenhagen Stroke Study. Am J Phys Med Rehabil. 2001; 80:685- 92.

Peigneux $\mathrm{P}$, van der Linden $\mathrm{M}$. Influence of ageing and educational level on the prevalence of body-part-as-objects in normal subjects. J Clin Exp Neuropsycho. 1999; 21:522-47.

Pharr V, Uttl B, Stark M, Litvan I, Fantie B, Grafman J. Comparison of apraxia in corticobasal degeneration and progressive supranuclear palsy. Neurology. 2001; 56:957-63.

Pramstaller PP, Marsden CD. The basal ganglia and apraxia. Brain. 1996; 119:319-40.

Rapcsak SZ, Crowswell SC, Rubens AB. Apraxia in Alzheimer's disease. Neurolog. 1989; 39:664-8.

Rapcsak SZ, Ochipa C, Anderson KC, Poizner H. Progressive ideomotor apraxia: evidence for a selective impairment of the action production system. Brain Cog. 1995; 27:213-36. 
Raymer AM, Maher LM, Foundas AL, Heilman KM, Rothi LJG. The significance of body part as tool errors in limb apraxia. Brain Cogn. 1997; 34:287-92.

Reis A, Castro-Caldas A. Illiteracy: A cause for biased cognitive development. J Int Neuropsychol Soc. 1997; 3:444-50.

Reis A, Petersson KM, Castro-Caldas A, Ingvar M. Formal schooling influences two but not three-dimensions naming skills. Brain Cogn. 2001; 47: 397-11.

Rothi LJ, Ochipa C, Heilman KM. A cognitive Neuropsychological Model of Limb Praxis. Cogn Neuropsychol. 1991; 8:443-58.

Rothi LJ, Heilman KM. Liepmann (1900 and 1905): A definition of apraxia and a model of praxis. In:Code C, Wallesch CW, Joanette Y, Lecours AR. editors. Classic Cases in Neuropsychology Erlbaurm: Psychology Press;1996. (Brain damage, behaviour and cognitive series).

Rock I, Ska B. Protocole d'évaluation de la reconnaissance de geste. Montréal: Laboratoire Th.-Alajouanine, Centre de recherche de I' Institut de Gériatrie de Montreal; 1994.

Ska B, Caramelli P, Croisile B, Fontaine FS, Gilbert B, Pineau H. Protocole d'Évaluation de la Production des Gestes, Montreal: Laboratoire Th.- 
Alajouanine, Centre de recherche de I' Institut de Gériatrie de Montreal; 1994.

Shumway-Cook A, Woollacott MH. Controle motor:Teoria e aplicações práticas. 1a ed.Barueri: Manole; 2003.

Taylor R. Motor apraxia in dementia. Percept Mot Skills.1994; 79:523-8.

Travniczek-Marerer A, Danielczyk W, Simanyi M, Fischer P. Ideomotor apraxia in Alzheimer's disease. Acta Neurol Scan. 1993; 88:1-4,.

van Heugten CM, Dekker J, Deelman BG, Stehmann-Saris FC, Kinebanian A. A diagnostic test for apraxia in stroke patients:internal consistency and diagnostic value. Clin Neuropsychol. 1999; 13:182-92.

Watson RT, Heilman KM. Callosal apraxia. Brain. 1983;106:391-403.

Wiederholt WC, Cahn D, Butters NM, Salmon DP, Kritz-Silverstein D, BarrettConnor E. Effects of age, gender and education on selected neuropsycological test in an elderly community cohort. J Am Geriatr Soc. 1993; 41:639-47. 
Yesavage JA, Books JO, Tinklenberg J. Development of aphasia, apraxia and agnosia and decline in Alzheimer's disease. Am J Psychiatry. 1993; $150: 742-7$. 


\section{APÊNDICE I}

\section{IDENTIFICAÇÃO}

NÚMERO DA AVALIACX̃̃O

\begin{tabular}{|c|c|}
\hline IDADE & \multirow{2}{*}{$\begin{array}{cc}\text { SEXO } & \text { DATA DA AVALIAÇÃO } \\
\text { ESCOLARIDADE }\end{array}$} \\
\hline DOMINÂNCIA & \\
\hline MEDICAMENTOS & \\
\hline MEEM & FLUENCIA V \\
\hline
\end{tabular}

\section{Produção de gestos}

\begin{tabular}{|l|l|l|}
\hline GESTOS & $\begin{array}{l}\text { COMANDO } \\
\text { VERBAL }\end{array}$ & IMITAÇÃO \\
\hline beber de copo & & \\
\hline usar um pente & & \\
\hline usar uma chave & & \\
\hline pregar um prego & & \\
\hline colocar óculos & & \\
\hline colocar uma aliança & & \\
\hline bater continência & & \\
\hline jogar um beijo & & \\
\hline dormir & NA & \\
\hline rezar & NA & \\
\hline colocar a palma da mão D sobre o olho D & NA & \\
\hline dorso da mão D sobre orelha E & NA & \\
\hline dedos indicador e médio em "V" & NA & \\
\hline perpendiculares à mesa & NA & \\
\hline braços cruzados com as mãos sobre os ombros & NA & \\
\hline anel duplo encadeado & & \\
\hline $\begin{array}{l}\text { mão D sobre orelha D com a palma da mão E sobre o } \\
\text { cotovelo D }\end{array}$ & & \\
\hline
\end{tabular}

\section{TESTE DE RECONHECIMENTO DO GESTO}

$1^{\circ}$ PARTE

\begin{tabular}{|l|l|l|l|l|l|l|l|}
\hline 1. & 2. & 3. & 4. & 5. & 6. & 7. & 8. \\
\hline 9. & 10. & 11. & 12. & 13. & 14. & 15. & 16. \\
\hline 17. & 18. & 19. & 20. & 21. & 22. & 23. & 24. \\
\hline 25. & 26. & 27. & 28. & 29. & 30. & 31. & 32. \\
\hline
\end{tabular}

2a Parte:

IMITAÇÃO DA UTILIZAÇÃO DOS OBJETOS (marcar as respostas corretas)

\begin{tabular}{|l|l|l|l|l|l|}
\hline 1. & 2. & 3. & 4. & 5. & 6. \\
\hline 7. & 8. & 9. & 10. & 11. & 12. \\
\hline
\end{tabular}

GESTOS CONVENCIONAIS (marcar as respostas corretas)

\begin{tabular}{|l|l|l|l|l|l|}
\hline 1. & 2. & 3. & 4. & 5. & 6. \\
\hline
\end{tabular}




\begin{tabular}{|l|l|l|l|l|l|l|l|}
\hline 1. & 2. & 3. & 4. & 5. & 6. & 7. & 8. \\
\hline 9. & 10. & 11. & 12. & 13. & 14. & 15. & 16. \\
\hline 17. & 18. & 19. & 20. & 21. & 22. & 23. & 24. \\
\hline
\end{tabular}

$4^{\mathrm{A}}$. PARTE

\begin{tabular}{|l|l|l|l|l|l|l|l|l|}
\hline 1. & 2. & 3. & 4. & 5. & 6. & 7. & 8. & 9. \\
\hline 10. & 11. & 12. & 13. & 14. & 15. & 16. & 17. & 18. \\
\hline
\end{tabular}

GESTOS CONVENCIONAIS (Citar o desejado e marcar os que foram corretamente selecionados)

\begin{tabular}{|l|l|}
\hline chamar com o dedo & bater palma \\
\hline cheiro ruim & dormir \\
\hline dar bronca & tapar os ouvidos \\
\hline
\end{tabular}

5. PARTE

NOMEAÇÃO

\begin{tabular}{|c|c|}
\hline PRIMEIRA PARTE & SEGUNDA PARTE \\
\hline 1. & 1. \\
\hline 2. & 2. \\
\hline 3. & 3. \\
\hline 4. & 4. \\
\hline 5. & 5. \\
\hline 6. & 6. \\
\hline 7. & 7. \\
\hline 8. & 8. \\
\hline 9. & 9. \\
\hline 10. & 10. \\
\hline
\end{tabular}


2 AVALIAÇÃO

Produção de gestos

\begin{tabular}{|l|l|l|}
\hline GESTOS & $\begin{array}{l}\text { COMANDO } \\
\text { VERBAL }\end{array}$ & IMITAÇÃO \\
\hline beber de copo & & \\
\hline usar um pente & & \\
\hline usar uma chave & & \\
\hline pregar um prego & & \\
\hline colocar óculos & & \\
\hline colocar uma aliança & & \\
\hline bater continência & & \\
\hline jogar um beijo & & \\
\hline dormir & NA & \\
\hline rezar & NA & \\
\hline colocar a palma da mão D sobre o olho D & NA & \\
\hline dorso da mão D sobre orelha E & NA & \\
\hline dedos indicador e médio em "V" & NA & \\
\hline perpendiculares à mesa & NA & \\
\hline braços cruzados com as mãos sobre os ombros & NA & \\
\hline anel duplo encadeado & & \\
\hline $\begin{array}{l}\text { mão D sobre orelha D com a palma da mão E sobre o } \\
\text { cotovelo D }\end{array}$ & \\
\hline
\end{tabular}

TESTE DE RECONHECIMENTO DO GESTO

$1^{\circ}$ PARTE

DECISÃO GESTUAL

\begin{tabular}{|l|l|l|l|l|l|l|l|}
\hline 1$)$ & $2)$ & $3)$ & $4)$ & $5)$ & $6)$ & $7)$ & $8)$ \\
\hline 9$)$ & $10)$ & $11)$ & $12)$ & $13)$ & $14)$ & $15)$ & $16)$ \\
\hline 17$)$ & $18)$ & $19)$ & $20)$ & $21)$ & $22)$ & $23)$ & $24)$ \\
\hline 25$)$ & $26)$ & $27)$ & $28)$ & $29)$ & $30)$ & $31)$ & $32)$ \\
\hline
\end{tabular}

2a Parte:

IMITAÇÃO DA UTILIZAÇÃO DOS OBJETOS (marcar as respostas corretas)

\begin{tabular}{|l|l|l|l|l|l|}
\hline 1$)$ & $2)$ & $3)$ & $4)$ & $5)$ & $6)$ \\
\hline 7$)$ & $8)$ & $9)$ & $10)$ & $11)$ & $12)$ \\
\hline
\end{tabular}

GESTOS CONVENCIONAIS (marcar as respostas corretas)

\begin{tabular}{|l|l|l|l|l|l|}
\hline 1$)$ & $2)$ & $3)$ & $4)$ & $5)$ & 6 (2) \\
\hline
\end{tabular}

3aPARTE

JULGAR SIMILARIDADE (marcar as respostas corretas)

\begin{tabular}{|l|l|l|l|l|l|l|l|}
\hline 1$)$ & $2)$ & $3)$ & $4)$ & $5)$ & $6)$ & $7)$ & $8)$ \\
\hline 9$)$ & $10)$ & $11)$ & $12)$ & $13)$ & $14)$ & $15)$ & $16)$ \\
\hline 17$)$ & $18)$ & $19)$ & $20)$ & $21)$ & $22)$ & $23)$ & $24)$ \\
\hline
\end{tabular}

$4^{\mathrm{A}}$. PARTE 
ESCOLHER O ATO CORRESPONDENTE AO OBJETO (marcar as respostas corretas)

\begin{tabular}{|l|l|l|l|l|l|l|l|l|}
\hline 1$)$ & $2)$ & $3)$ & $4)$ & $5)$ & $6)$ & $7)$ & $8)$ & 9 ) \\
\hline 10$)$ & $11)$ & $12)$ & $13)$ & $14)$ & $15)$ & $16)$ & $17)$ & $18)$ \\
\hline
\end{tabular}

GESTOS CONVENCIONAIS (Citar o desejado e marcar os que foram corretamente selecionados)

\begin{tabular}{|l|l|}
\hline chamar com o dedo & bater palma \\
\hline cheiro ruim & dormir \\
\hline dar bronca & tapar os ouvidos \\
\hline
\end{tabular}

5. PARTE

NOMEAÇÃO

\begin{tabular}{|l|l|}
\hline PRIMEIRA PARTE & SEGUNDA PARTE \\
\hline 1 & $1)$ \\
\hline 2 & $2)$ \\
\hline 3 & $3)$ \\
\hline 4 & $4)$ \\
\hline 5 & $5)$ \\
\hline 6 & $6)$ \\
\hline 7 & $7)$ \\
\hline 8 & $8)$ \\
\hline 9 & $9)$ \\
\hline 10 & $10)$ \\
\hline
\end{tabular}




\section{APÊNDICE II}

Lista dos gestos solicitados no protocolo de produção de gestos

- Beber de um copo

- Usar um pente para pentear o cabelo

- Usar uma chave para abrir uma porta

- Pregar um prego

- Colocar óculos

- Colocar uma aliança

- Bater continência

- Jogar um beijo

- Dormir

- Rezar

- Colocar a palma da mão D sobre o olho D

- Dorso da mão D sobre a orelha $E$

- Dedos indicador e médio em "V"

- Os gestos solicitados estão descritos no anexo A.

- Mão perpendicular a mesa, com a palma da mão voltada para o corpo do sujeito.

- Braços cruzados com a mão sob os ombros

- Anel duplo (formado pelo indicador e polegar de ambas as mãos) encadeado

- Palma de mão $D$ sob a orelha $D$, mão $E$ sobre o cotovelo $D$. 


\section{APÊNDICE III}

Lista de gestos do protocolo de reconhecimento de gestos.

A letra "U" na frente da descrição do gesto significa que é um gesto

unimanual e a letra "B" significa que é um gesto bimanual.

PRIMEIRA PROVA : SELEÇÃO DE GESTOS (gestos com significado versus gestos sem significado).

\section{Exemplos:}

1. Bocejar

2. Mão fechada sob o queixo

3. Tocar flauta

Lista dos 32 gestos:

(s) gestos com significados (16) (so) uso de objetos (8)

(sc) gestos convencionais (8)

(d) gestos desprovidos de significado (de) estáticos

(dd) dinâmicos

1. (U) Index e dedo médio em "A" em cima da mesa, polegar e dedo mínimo voltados para o alto, com os demais dedos em flexão (dd)

2. (B) Mão direita com os dedos em flexão e mão esquerda aberta. A mão que está fechada se abre e a que está aberta se fecha sucessivas vezes (dd)

3. (B) Dizer a qualquer um que vai dormir (sc)

4. (B) Tocar piano (so)

5. (B) Dedos mínimo apontando para as bochechas com a palma da mão voltada para baixo. demais dedos flexionados(de)

6. (U) Mão direita apontada para a bochecha direita com a palma direcionada para baixo (de)

7. (U) Mão direita fechada com uma pequena abertura entre os dedos, com a face lateral sobre a mesa, mão direita fechada no ombro esquerdo e dorso da mão direta sobre a bochecha esquerda (dd)

8. (B) Colocar uma aliança (so) 
9. (U) Dedos da mão direita perpendiculares a mesa, com a palma da mão voltada para o corpo do indivíduo (de)

10. (B) Dorso da mão direita no queixo e palma da mão esquerda sobre a cabeça (de)

11. (U) Beber um copo de água (so)

12. (U) Girar uma chave em uma fechadura. (so)

13. (U) Mostrar que está sentindo mau cheiro (sc)

14. (B) Palma direita sobre o dorso da mão esquerda, colocando-se perpendicular e paralela a esta alternadamente (dd)

15. (U) Pentear o cabelo (so)

16. (U) Polegar direito girando em torno do queixo (dd)

17. (U) Chamar uma pessoa (sc)

18. (U) Jogar um beijo com a mão (sc)

19. (B) Anel duplo encadeado, mãos cruzadas sobre os ombros (dd)

20. (B) Colocar uma touca, ou chapéu ou boné (so)

21. (B) Passar os braços horizontalmente a frente do tronco, com a palma da mão direita apontando para lateral e mão esquerda para frente(de)

22. (B) Virar a página de um jornal, ler jornal (so)

23. (U) Dorso da mão direita na orelha esquerda (de)

24. (U) Punho-palma-lado (dd)

25. (U) Pedir silêncio (sc)

26. (U) Bater continência (sc)

27. (B) Punho fechado com uma fenda entre os dedos, a mão direita passa sobre a mão esquerda e depois retorna a posição inicial sucessivas vezes (sd)

28. (B) Braços paralelos na frente do tronco, sobre a mesa com o lado da mão direita apontando para baixo, mão esquerda com flexão de dedos e dorso da mão apontando para cima. (se) 
29. (U) Mexer o açúcar com uma colher (so)

30. (U) Dar uma bronca (sc)

31. (B) Suplicar com as mãos (sc)

32. (U) Indicador, polegar e dedo mínimo da mão direita juntos sobre o ombro esquerdo (de).

\section{SEGUNDA PROVA : DIFERENCIAÇÃO ENTRE GESTOS BEM EXECUTADOS E GESTOS MAL EXECUTADOS}

\section{Exemplo:}

1. Tocar flauta

2. Direcionar a flauta para cima (erro de orientação)

Lista dos 12 pares de gestos

$\begin{array}{ll}\text { (o) erro de orientação (6) } & \text { (p) erro de preensão (6) }\end{array}$

1. (U) 1)Escrever com uma caneta; 2) Segurar a caneca com a mão muito aberta $(p)$

2. (B) 1)Olhar com auxílio de um binóculo; 2) Posicionar o binóculo nas sobrancelhas (0)

3. (U) 1)Segurar o pincel pelas cerdas com os cinco dedos com a palma da mão voltada para o alto (p); 2) Pintar um muro com um pincel

4. (U) 1)Atender ao telefone; 2) Rotação de $180^{\circ}$ do receptor (o)

5. (U) 1)Fumar um cigarro; 2) Cigarro preso entre os dedos com punho em posição neutra de prono-supinação (o)

6. (B) 1)Pregar um prego; 2) Cabo do martelo do lado oposto ao do corpo do sujeito (o)

7. (B) 1)Colocar as pernas dos óculos no pescoço (o);2) Colocar os óculos

8. (B) 1) Preensão da lixa de unha como se fosse um cigarro (p); 2) Lixar as unhas 
9. (B) 1)Escovar os dentes na vertical com o cabo da escova voltado para baixo (o); 2) Escovar os dentes

10. (U) 1)Passar uma roupa; 2) Preensão do cabo do ferro com a palma da mão voltada para cima $(p)$.

11. (B) 1)Palma da mão aberta (p); 2) Desatarraxar a tampa de uma garrafa

12. (B) 1)Segurar o cabo do serrote com a mão fechada, polegar vertical, index apontado para frente e dedo médio horizontal (p); 2) Serrar um pedaço de madeira.

\section{Exemplo:}

1. Bocejar

2. Dorso da mão nos lábios (erro de orientação)

Lista dos 6 pares de gestos

$\begin{array}{ll}\text { (o) erro de orientação (3) } & \text { (f) erro de forma (3) }\end{array}$

1. (B) 1)Colocar o dorso da mão nas orelhas (o);2) Sinalizar que há muito barulho.

2. (U) 1)Fazer o gesto com a mão fechada (f) ; 2) Dizer a uma pessoa que ela deve sair

3. (U) 1)Dizer que a refeição está deliciosa; 2) Fazer o gesto com a mão fechada (f)

4. (B) 1) Fazer o gesto com a mão fechada (f); 2) Contar os dedos

5. (B) 1)Dedos da mão esquerda apontados para a direita e palma da mão direita apoiada na mesa e apontada para a esquerda (o);2) Jurar dizer a verdade

6. (U) 1)Mostrar o número dois; 2) Dedos apontados para baixo (o).

\section{TECEIRA PROVA : JULGAMENTO DE SIMILARIDADE}

\section{Exemplo:}

1. Aplaudir (duas mãos paralelas) 
2. Aplaudir (duas mãos perpendiculares)

Lista dos 24 pares de gestos

(mi) Pares mostram a mesma ação feita de maneira idêntica.: (4)

(md) Pares mostram a mesma ação feita de maneira diferente. (8)

(d) Pares mostram ações diferentes (12)

1. (B) (2 vezes) Fechar o zíper de um casaco. (mi)

2. (U) 1. Escovar o dente de baixo para cima; 2. Escovar o dente da esquerda para a direita $(\mathrm{md})$

3. (B) 1. Colocar as mãos como se estivesse em oração (palmas coladas e dedos também colados; 2 . Colocar a mão como se estivesse em oração (dedos entrelaçados) (md)

4. (B) 1. Dirigir um veículo com as duas mãos; 2. Dirigir um veículo com as duas mãos, porém virando o volante para a direita $(\mathrm{md})$

5. (U) 1. Atirar com um revólver; 2. Lavar a janela com um pano (d)

6. (B) 1. Colocar lente de contato; 2. Limpar o nariz com um lenço de papel (d).

7. (B) 1. Telefonar usando um aparelho analógico de discar; 2. Telefonar usando um aparelho de teclas (md)

8. (U) 1. Passar perfume com um vaporizador; 2. Regar uma planta com um regador $(d)$

9. (B) 1.Tocar violino; 2. Distribuir cartas (d)

10. (B) (2 vezes) Secar o cabelo com uma toalha (mi)

11. (B) 1. Abrir uma gaveta; 2. Desatarraxar a tampa de uma garrafa (d)

12. (U) 1. Olhar ao longe com uma luneta; 2. Passar rímel nos cílios (d)

13. (U) 1. Virar a página de um livro com o polegar e o índex; 2. Virar a página de um livro com toda a mão (md)

14. (B) 1. Datilografar; 2. Abrir um guarda chuva manual (d)

15. (M) 1. Passar batom; 2. Fazer a barba com um barbeador elétrico (d)

16. (M) 1. Beber de um copo; 2. Beber de uma xícara (md) 
17. (B) 1. Colocar uma echarpe em torno do pescoço; 2. Colocar um brinco (d)

18. (B) 1. Espalhar creme no rosto; 2. Colocar um colar (d)

19. (U) 1. Passar maquiagem na bochecha com um pincel; 2. Passar perfume (d)

20. (2 vezes) Torcer um pano molhado (mi)

21. (U) 1. Pintar passando o pincel de baixo para cima; 2. Pintar passando o pincel da esquerda para a direita $(\mathrm{md})$

22. (U) 1. Dar tchau (dedos separados, mão da direita para a esquerda); 2. Dar tchau (dedos unidos, flexionando parcialmente os dedos) (md)

23. (U) (2 vezes) Colocar uma pastilha na boca (mi)

24. (U) 1. Bater à porta; 2. Lançar uma bola (d).

QUARTA PROVA : SELEÇÃO DO GESTO CORRETO

Exemplo: Imagem: agulhas de tricot

1. Tricotar

2. Tocar flauta

Lista dos 18 gestos

$\begin{array}{lll}\text { (f) erros de forma } 6 & \text { (m) erros de movimento } 6 & \text { (sl) sem ligação } 6\end{array}$

1 (U) Pinça de depilar a sobrancelha

1. Acender um isqueiro (sl)

2. Depilar a sobrancelha

2. (U) Escova de dentes

1. Escovar os dentes

2. Fazer a barba com um barbeador $(\mathrm{m})$

3.(B) Saco de salgadinho

1. Comer o salgadinho

2. Abrir uma gaveta (sl) 
4. (B) Binóculo

1. Olhar com auxílio do binóculo

2. Procurar algum lugar (f)

5. (U) Regador de plantas

1. Mexer o açúcar do café com uma colher $(\mathrm{m})$

2. Regar uma planta

6. (U) Caneta

1. Escrever com uma caneta

2. Cortar uma folha de papel com uma tesoura (sl)

7. (U) Ferro de passar

1. Passar uma roupa

2. Limpar uma mesa com um pano

8. (U) Vidro de perfume

1. Sentir o perfume do vidro

2. Assobiar um apito $(\mathrm{m})$

9. Lixa de unha

1. Lixar uma unha

2. Passar esmalte na unha (m)

10. Cigarro

1. Tomar sopa com uma colher (f)

2. Fumar um cigarro

11. Martelo

1.Apertar um parafuso com uma chave de fenda $(\mathrm{m})$

2. Pregar um prego

12. Garrafa

1. Desatarraxar a tampa de uma garrafa

2. Abrir um guarda-chuva manual (sl)

13. Serrote

1. Distribuir cartas (sl)

2. Serrar um pedaço de madeira

14. Pincel

1. Jogar ping-pong $(m)$

2. Pintar um muro com um pincel

15. Telefone

1. Discar o telefone

2. Lamber uma bola de sorvete de massa (sl) 
16. Óculos

1. Colocar fone de ouvido (f)

2. Colocar os óculos

17. Saleiro

1. Salgar a comida

2. Dizer que qualquer coisa não é boa (polegar voltado para baixo)

18. Livro

1.Colocar um selo em uma folha

2. Virar a página de um livro

Exemplo: Ação:Bocejar

1. Bocejar

2. Pedir carona

1. Ação: Chamar uma pessoa

1. Número dois

2. Chamar uma pessoa

2. Ação: Mostrar que está sentindo mau cheiro

1.Dizer que a refeição está deliciosa

2. Mostrar que está sentindo mau cheiro

3. Ação: Dar uma bronca

1.Dar uma bronca

2. Dizer a uma pessoa que ela deve sair

4. Ação: Bater palmas

1.Jurar dizer a verdade

2.Bater palmas

5.Ação: Dizer a qualquer um que vai dormir

1. Dizer a qualquer um que vai dormir

2. Contar os dedos

6.Ação: Sinalizar que há muito barulho.

1. Sinalizar que há muito barulho

2. Suplicar com as mãos 
Lista dos 10 gestos

1. Mexer o açúcar do café com uma colher

2. Lavar as mãos

3. Se pentear com um pente

4. Abrir um jornal

5. Girar uma chave em uma fechadura

6. Beber um copo de água

7. Colocar uma touca

8. Colocar uma aliança

9. Tocar piano

10.Salgar a comida

Lista dos 10 gestos

1. Chamar uma pessoa

2. Suplicar com as mãos

3. Mostrar que está sentindo mau cheiro

4. Jogar um beijo com a mão

5. Dar tchau

6. Dar uma bronca

7. Bater continência

8. Pedir silêncio a qualquer um

9. Dizer a qualquer um que vai dormir

10. Bater palmas 
APÊNDICE IV 
